\title{
Structure of the DEAH/RHA ATPase Prp43p bound to RNA implicates a pair of hairpins and motif Va in translocation along RNA
}

\author{
YANGZI HE, ${ }^{1}$ JONATHAN P. STALEY, ${ }^{2}$ GREGERS ROM ANDERSEN, ${ }^{1}$ and KLAUS H. NIELSEN ${ }^{2}$ \\ ${ }^{1}$ Department of Molecular Biology and Genetics, Aarhus University, DK8000 Aarhus C, Denmark \\ ${ }^{2}$ Department of Molecular Genetics and Cell Biology, University of Chicago, Chicago, Illinois 60637, USA
}

\begin{abstract}
Three families of nucleic acid-dependent ATPases (DEAH/RHA, Ski2-like, and NS3/NPH-II), termed the DExH ATPases, are thought to execute myriad functions by processive, ATP-dependent, $3^{\prime}$ to $5^{\prime}$ translocation along single-stranded nucleic acid. While the mechanism of translocation of the viral NS3/NPH-II family has been studied extensively, it has not been clear if or how the principles that have emerged for this family extend to the other two families. Here we report the crystal structure of the yeast DEAH/RHA family ATPase Prp43p, which functions in splicing and ribosome biogenesis, in complex with poly-uracil and a nonhydrolyzable ATP analog. The structure reveals a conserved DEAH/RHA-specific variation of motif Ib within the RecA1 domain of the catalytic core, in which the motif elongates as a $\beta$-hairpin that bookends the $3^{\prime}$ end of a central RNA stack, a function that in the viral and Ski-2 families is performed by an auxiliary domain. Supporting a fundamental role in translocation, mutations in this hairpin abolished helicase activity without affecting RNA binding or ATPase activity. While the structure reveals differences with viral ATPases in the RecA1 domain, our structure demonstrates striking similarities with viral ATPases in the RecA2 domain of the catalytic core, including both a prominent $\beta$-hairpin that bookends the $5^{\prime}$ end of the RNA stack and a dynamic motif $\mathrm{Va}$ that is implicated in mediating translocation. Our crystal structure, genetic, and biochemical experiments, as well as comparisons with other DExH ATPases, support a generalized mechanism for the DExH class of helicases involving a pair of bookends that inchworm along RNA.
\end{abstract}

Keywords: DEAH/RHA; Prp43p; structure; splicing; ribosomal biogenesis

\section{INTRODUCTION}

Essentially all RNA-dependent processes require RNA-dependent ATPases of the SF1 and SF2 superfamilies of helicases (Tanner and Linder 2001; Ozgur et al. 2015). These conserved superfamily members hydrolyze ATP in an RNA-dependent manner to catalyze conformational rearrangements in RNA or ribonucleoprotein complexes (RNPs). Similar to DNA-dependent ATPases of SF1 and SF2, these RNA-dependent ATPases share a conserved core of two RecA-like domains (RecA1 and RecA2) that contain approximately a dozen characteristic sequence motifs involved in binding of RNA, binding and hydrolysis of ATP, and coupling these functions (Fairman-Williams et al. 2010). Variations in these motifs together with other sequence-, structural-, and mechanisticvariations have been used to define distinct families (Fairman-Williams et al. 2010), including four SF2 families that can unwind RNA: the DEAH/RHA, viral NS3/NPH-II,

Corresponding authors: jstaley@uchicago.edu,gra@mbg.au.dk,khn@ uchicago.edu

Article is online at http://www.rnajournal.org/cgi/doi/10.1261/rna.060954. 117.
Ski2-like, and DEAD-box families. The DEAH/RHA, NS3/ NPH-II, and Ski2-like families, collectively referred to as the DExH-box ATPases, bind RNA in an ATP-independent manner and unwind duplex RNA in an ATP-hydrolysis-dependent manner. The mechanism is thought to involve processive, $3^{\prime}$ to $5^{\prime}$ translocation on single-stranded (ss) RNA, because DExH-box ATPases can unwind relatively long RNA duplexes and require a ssRNA $3^{\prime}$ overhang flanking the duplex region of the substrate (Pyle 2008; Jankowsky 2011). In contrast, DEAD-box ATPases bind RNA in an ATP-dependent manner and unwind short duplexes by binding to and distorting one strand of the duplex while ATP hydrolysis appears to be required for product release (Jankowsky 2011). Although the DExH-box ATPase families share fundamental biochemical activities, the distinct motifs and auxiliary domains that define each family may reflect the unique substrates and specialized mechanisms of the families. Indeed,

(c) $2017 \mathrm{He}$ et al. This article is distributed exclusively by the RNA Society for the first 12 months after the full-issue publication date (see http:// rnajournal.cshlp.org/site/misc/terms.xhtml). After 12 months, it is available under a Creative Commons License (Attribution-NonCommercial 4.0 International), as described at http://creativecommons.org/licenses/by-nc/4.0/. 
structural and biochemical studies of the viral NS3/NPH-II and the Ski2-like families have, in addition to highlighting common elements, implicated distinct elements in RNA unwinding and directional translocation (Kim et al. 1998; Büttner et al. 2007; Gu and Rice 2010; Appleby et al. 2011). Still, the mechanism of translocation by the DExH-box ATPases remains under investigation. Further, the elements within the DEAH/RHA ATPases that enable translocation are less well understood.

Prp43p is an excellent model ATPase for the DEAH/RHA ATPase family. The protein is conserved throughout eukaryotic species and is required for both ribosome biogenesis and splicing (Arenas and Abelson 1997; Martin et al. 2002; Lebaron and Froment 2005; Combs et al. 2006; Leeds et al. 2006; Mayas et al. 2010; Fourmann et al. 2016). As with some other members of the DEAH/RNA family, the substrate specificity and activity of Prp43p requires direct interaction with one of four G-patch proteins named Ntrlp, Pfalp/ Sqs1p, Gnolp/Pxrlp, or Cmg1, which all have a characteristic glycine-rich domain (Tanaka and Schwer 2006; Tanaka et al. 2007; Lebaron et al. 2009; Chen et al. 2014; RobertPaganin et al. 2015; Heininger et al. 2016). Further, mutational analysis of the conserved motifs in Prp43p have identified residues important for RNA binding, ATP hydrolysis, and RNA unwinding (Martin et al. 2002; Tanaka and Schwer 2006; Tanaka et al. 2007; Walbott et al. 2010).

Crystal structures of Prp43p bound to ADP revealed the organization of domains and localization of conserved motifs that characterize the DEAH/RHA family (He et al. 2010; Walbott et al. 2010; Tauchert et al. 2016) and pinpointed similarities with and differences from the NS3/NPH-II and Ski2like families. As in the NS3/NPH-II family (Gu and Rice 2010; Appleby et al. 2011), in Prp43p a large $\beta$-hairpin ( $\beta$-HP) emerges from the RecA2 domain between motifs $\mathrm{V}$ and VI and extends to interact with auxiliary domains ( $\mathrm{He}$ et al. 2010; Walbott et al. 2010); this $\beta$-HP is conserved throughout the DEAH/RHA and NS3/NPH-II families (He et al. 2010; Walbott et al. 2010; Jankowsky 2011; Prabu et al. 2015). In NS3/NPH-II ATPases, the $\beta$-HP acts as a bookend at the $5^{\prime}$ end of a central stack of bases in the RNA substrate and is consequently designated the $5^{\prime} \mathrm{HP}$ (Gu and Rice 2010). In Ski2like ATPases, including Ski2, Mtr4, and Hel308, a conserved $\beta$-HP emerges from the same position of the RecA2 domain, but the $\beta$-HP is shorter and does not interact with auxiliary domains (Büttner et al. 2007; Jackson et al. 2010; Halbach et al. 2012); instead, this $\beta$-HP, as shown in Hel308, can interact directly with a duplex substrate in a manner that has been proposed to promote strand separation (Büttner et al. 2007). While the $\beta$-HPs of Prp43p and NS3/NPH-II ATPases are similar, the auxiliary domains of Prp43p differ from those of the NS3/NPH-II ATPases but are similar to those of the Ski2-like ATPases, in which the RecA2 domain is followed first by a winged-helix (WH) domain and then by a helical bundle (HB) domain (Büttner et al. 2007; Pena et al. 2009; He et al. 2010; Jackson et al. 2010; Walbott et al. 2010;
Halbach et al. 2012; Nguyen et al. 2013). The HB domain includes a "ratchet helix" that in Ski2-like ATPases has been proposed to promote directionality in unwinding (Büttner et al. 2007). In Prp43p, the HB domain is followed by an OB-like fold (He et al. 2010; Walbott et al. 2010), which is conserved among and specific to DEAH/RHA ATPases (Kudlinzki et al. 2012; Prabu et al. 2015) and is thought to be the target of the regulatory G-patch proteins (Walbott et al. 2010). While similarities of the Prp43p structures with NS3/NPH-II and Ski2-like structures suggest parallels in their translocation mechanisms, general mechanistic features would necessarily manifest differently given the substantial sequence differences, and deeper insight has awaited a structure of Prp43p bound to RNA and ATP.

Here we report the crystal structure, determined at $4.2 \AA$ resolution, of budding yeast Prp43p bound to single-stranded poly-uracil and the nonhydrolyzable ATP analog ADPNP. While the structure shows similarities to the recent structure of the DEAH/RHA ATPase MLE bound to RNA and the transition state analog $\mathrm{ADP}-\mathrm{AlF}_{4}$ (Prabu et al. 2015), the new structure of Prp43p enabled a direct investigation of the consequences of binding RNA and ATP, through a comparison with the structure of Prp43p-ADP, also derived from budding yeast (He et al. 2010; Walbott et al. 2010). The comparison revealed that the parallel between the RecA2 domains of Prp43p and NS3 extends from the long $\beta$-HP, which similarly bookends a central RNA stack, to include, intriguingly, conformational rearrangements of motif $\mathrm{Va}$ in RecA2 (Gu and Rice 2010; Appleby et al. 2011), thereby implicating this motif as a general ATP-dependent switch that enables translocation. Whereas NS3/NPH-II utilizes an auxiliary domain to bookend the $3^{\prime}$ end of the central RNA stack (Frick 2007; Gu and Rice 2010; Appleby et al. 2011), we report structural and functional evidence that in Prp43p this role is fulfilled by the RecAl motif Ib, which adopts an elongated $\beta$-HP and utilizes DEAH/RHA-specific, conserved residues for the bookend. Lastly, our findings support a mechanism for translocation by DEAH/RNA and Ski2-like ATPases that is similar to NS3/NP-II ATPases.

\section{RESULTS}

\section{Structure of Prp43p bound to ADPNP and RNA}

To gain insight into how DEAH/RHA ATPases, in general, and Prp43p, in particular, remodel RNP substrates in an ATP-dependent manner, we determined the structure of $S$. cerevisiae Prp43p in complex with ADPNP and a singlestranded poly-uracil $\left(\mathrm{U}_{25}\right)$ RNA oligo to $4.2 \AA$ resolution (Table 1; Fig. 1A). The crystallographic asymmetric unit contains two complexes, $\mathrm{A}$ and $\mathrm{B}$, which each include protein, RNA, and ADPNP in highly similar conformations. A $2 \mathrm{mF}_{\mathrm{o}}-\mathrm{DF}_{\mathrm{c}}$ electron density map in which atoms from RNA were omitted during map calculation revealed clear and continuous density juxtaposed with and flanking the putative 
TABLE 1. Statistics for data collection and model refinement

\begin{tabular}{ll}
\hline Data collection and processing & MAX-lab I911-3/1.000 \\
Beam line/ $\lambda(\AA)$ & $\mathrm{P} 2{ }_{1} 2_{1} 2$ \\
Space group & $79.37,154.05,169.22$ \\
Unit cell parameters $a, b, c(\AA)$ & $30.00-4.20(4.34-4.20)$ \\
Resolution $(\AA)$ & $27.9(115.2)$ \\
$R_{\text {meas }}(\%)$ & $8.67(2.08)$ \\
$l / \sigma l$ & $99.5(99.9)$ \\
Completeness (\%) & $6.05(6.22)$ \\
Redundancy & $0.990(0.751)$ \\
CC $(1 / 2)$ & \\
Refinement & $30.00-4.20(4.34-4.20)$ \\
Resolution $(\AA)$ & 15,493 \\
No. reflections & $26.03 / 28.61$ \\
$R_{\text {work }} / R_{\text {free }}(\%)$ & $12,098 / 42 / 434$ \\
No. atoms (protein/ADPNP/RNA) & 0.002 \\
R.m.s.d. bond lengths $(\AA)$ & 0.567 \\
R.m.s.d. angles $\left({ }^{\circ}\right)$ & 149.2 \\
Average $B$ values $\left(\AA^{2}\right)$ & $93.4 / 5.8 / 0.8$ \\
Ramachandran plot $(\%)($ favored/ & \\
allowed/outliers) &
\end{tabular}

Values in parentheses are for outer resolution shell. $R_{\text {meas }}=\left(\sum_{h k l}\right.$ $\left.\sqrt{(}(n /(n-1)) \sum_{\mathrm{j}=1}^{n}\left|I_{h k l, j}-<l_{h k l}>\right|\right) / \sum_{h k l} \sum_{\mathrm{j}} \mathrm{l}_{h k l, j}$ for the intensity of reflection $h k l$ measured $n$ times. $R$-factor $=\left(\sum_{h}|| F_{\mathrm{o}}|-k| F_{\mathrm{c}}|| /\right.$ $\left.\sum_{\mathrm{h}}\left|F_{\mathrm{o}}\right|\right)$, where $F_{\mathrm{o}}$ and $F_{\mathrm{c}}$ are the observed and calculated structure factor, respectively, and $k$ is a scaling factor. $R_{\text {free }}$-factor is identical to the $R$-factor on a subset of test reflections not used in refinement. CC $(1 / 2)$ is the correlation between intensities from random half-data set.

RNA binding site of Prp43p (Fig. 1B; Supplemental Fig. S1A). The RNA was built with $5^{\prime}$ to $3^{\prime}$ polarity relative to RecA2 and RecA1, respectively, as observed for all SF1 and SF2 ATPases (Pyle 2008), and the electron density was most consistent with this polarity. In addition to the nine nucleotides observed in both complexes, in complex B four additional RNA nucleotides were resolved at the $3^{\prime}$ end (Fig. 1B; Supplemental Fig. S1A). While three HB domain residues in close proximity to the $3^{\prime}$ end (Y595, Y610, S614, Supplemental Fig. S1B) have been cross-linked to ssRNA in a manner stimulated by the G-patch factor Ntr1 (Christian et al. 2013), this 3' tail may be stabilized by crystal packing (Supplemental Fig. S1C), because even triple mutations of the above residues did not yield growth phenotypes in budding yeast (data not shown). Still, as complex B has a lower average B-factor than complex A (144 versus $151 \AA^{2}$ ), and this difference is even more pronounced comparing the RNA residues $1-9$ in each complex, we chose to focus on complex B.

The structure determination of the Prp43p-RNA-ADPNP complex was assisted by our Prp43p-ADP structure determined at $2.2 \AA$ (He et al. 2010). Further, we maintained a very tight stereochemistry and enforced tight noncrystallographic symmetry restraints during refinement and used imDFF (Croll and Andersen 2016) to minimize close contacts, resulting in final $R_{\text {work }}$ and $R_{\text {free }}$ values of $26.0 \%$ and $28.6 \%$, respectively (Table 1 ). While the structure is based on low resolution data that preclude a precise definition of side chain conformation and interactions between protein and RNA or ADPNP, our model is likely reliable in terms of the backbone conformation and the overall direction of the side chains. The two Prp43p molecules in the asymmetric unit superimpose with a root mean square deviation (RMSD) of $0.53 \AA$ over $752 \mathrm{C}_{\alpha}$ atoms. Further, the RecA domains superimpose with an RMSD of $0.8 \AA$ over $247 \mathrm{C}_{\alpha}$ atoms with the RecA domains of the DEAH/RHA ATPase MLE, determined at a resolution of $2.1 \AA$ in complex with a $\operatorname{poly}(\mathrm{U})$ RNA and $\mathrm{ADP}_{-} \mathrm{AlF}_{4}$ (Prabu et al. 2015). Overall, the structure allows us to clearly visualize the ADPNP, the RNA, and conformational changes in Prp43p resulting from the binding of RNA and ADPNP as verified by omit maps (Fig. 1B; Supplemental Fig. S1A,D,E).

\section{Overall architecture}

As already observed in the Prp43p-ADP structure (He et al. 2010; Walbott et al. 2010; Tauchert et al. 2016), the Prp43p-ADPNP-RNA structure exhibits a six-domain architecture, with an N-terminal domain (NTD), RecAl and RecA2 domains, a WH domain, an HB domain, and a C-terminal domain (CTD) with an OB-like fold (Fig. 1A). The structure reveals that the two RecA domains of Prp43p, as in other SF1 and SF2 ATPases, (i) form a composite binding site for ADPNP (Fig. 1A), (ii) adopt a closed conformation characteristic of an ATP-bound state (Ozgur et al. 2015) (see below), and (iii) positions RNA binding motifs along a surface-oriented orthogonal to the ADPNP binding pocket - to engage the phosphodiester backbone of four stacked residues (Fig. 2A,B). As in Ski2-like ATPases (Büttner et al. 2007), the WH and HB domains enclose the RNA stack, yielding an RNA channel (Figs. 1A, 2C,D). The $5^{\prime}$ entrance to the channel is composed of the $\mathrm{HB}$ domain, the OB-like fold, and the RecA2 domain, including the prominent $\beta$-HP (Fig. 2C), while the $3^{\prime}$ exit of the channel is formed by the $\mathrm{WH}, \mathrm{HB}$, and RecAl domains (Fig. 2D). As in NS3 (Gu and Rice 2010; Appleby et al. 2011), this $\beta$-HP at the $5^{\prime}$ end extends from RecA2 to cap the RNA stack (Fig. 1B,C), and consequently we refer to the $\beta$-HP as the $5^{\prime} \mathrm{HP}$; the HP extends even further to reach auxiliary domains-in Prp43p, the OB-like fold and WH domain (Fig. 1A). While in Ski2-like helicases the interaction of a corresponding, shorter $5^{\prime} \mathrm{HP}$ with a single-stranded/double-stranded DNA junction suggested a direct role in unwinding (Büttner et al. 2007), a distinct spatial position of the $5^{\prime} \mathrm{HP}$ in MLE did not support such a role in DEAH/ RHA helicases (Prabu et al. 2015), and our structure of Prp43p supports this interpretation.

\section{Structural model of RNA binding by Prp43p suggests both conserved and unique interaction modes}

The ADP-Prp43p structure revealed an occluded RNA binding pocket that precludes entry of RNA (He et al. 2010). In 


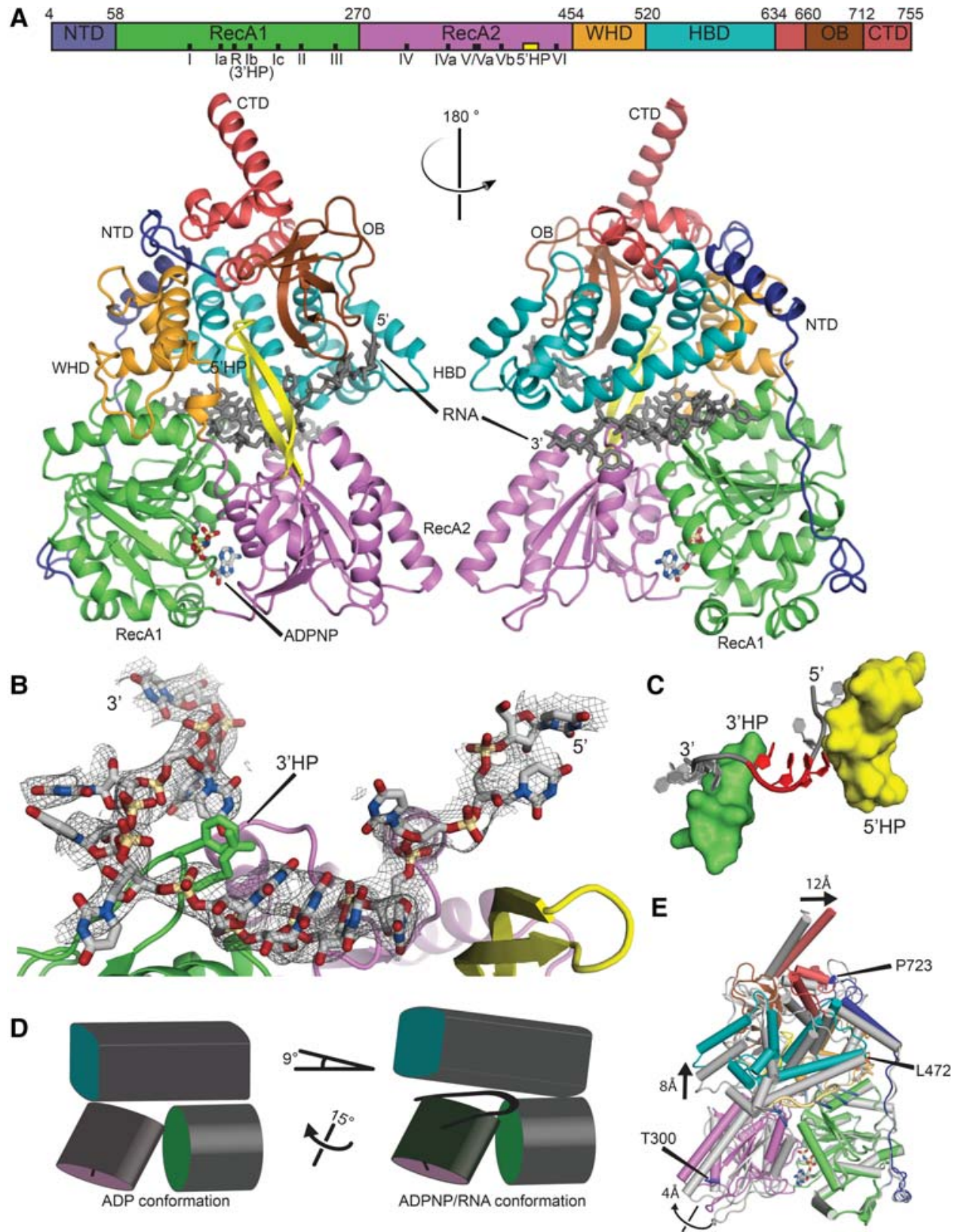

FIGURE 1. Overview of structure of Prp43p bound to an ATP analog and single-stranded RNA. (A) Schematic of S. cerevisiae Prp43p and its structure bound to ADPNP and a single-stranded poly(U) RNA. The schematic (top) illustrates positions of domains and conserved motifs. The structure (bottom) is shown in two orientations. The NTD is colored dark blue; RecAl, green; RecA2, magenta; the $5^{\prime} \mathrm{HP}$, yellow; the WH domain, orange; the ratchet domain, teal; the CTD, red; the OB-like fold, brown; the RNA, gray; and ADPNP, multiple colors according to atoms. $(B) \mathrm{A}_{2} \mathrm{mF}_{\mathrm{o}}-\mathrm{DF}_{\mathrm{c}}$ electron density omit map surrounding the RNA in complex B is shown, nonaveraged and contoured at $0.8 \sigma$. For clarity, only the RecA1 and RecA2 domains are shown; the RNA is colored according to atom type. $(C)$ Surface representation of the $5^{\prime} \mathrm{HP}$ and $3^{\prime} \mathrm{HP}$, shown bookending the stack of four, intervening bases colored red. $(D)$ Schematic representation of the domain rearrangements in the ADPNP-RNA structure of Prp43p, relative to the ADP structure (PDB 3KX2). The RecA domains are represented as cylinders, with the end of RecA1 colored green and RecA2, magenta; the auxiliary domain is represented as a box, and the RNA, as a black line. Both the rotation of RecA2 and the tilting of the auxiliary domain is indicated. (E) Comparison of the structures of Prp43p in the ADP-bound (gray) and the ADPNP-RNA-bound (colored) states, with the RecAl domains (green) superimposed. Straight arrows indicate the tilt of the auxiliary domain; the curved arrow shows the rotation of RecA2 around the indicated axis. The location of reference residues, L472 (defining pivot point of the tilt) and T300/P723 (defining axis of rotation), are indicated.

our RNA-ADPNP-Prp43p structure, opening of the RNA binding pocket is made possible, in part, by a coordinated $\sim 9^{\circ}$ tilt of the WH domain, the HB domain, and CTD, relative to the RecAl domain (Fig. 1D,E). These three domains superimpose between the ADP and RNA-ADPNP structures with an RMSD of $0.52 \AA$ for $252 \mathrm{C}_{\alpha}$ atoms, suggesting that these domains form a single rigid structural unit, which we will refer to collectively as the "auxiliary domains." 


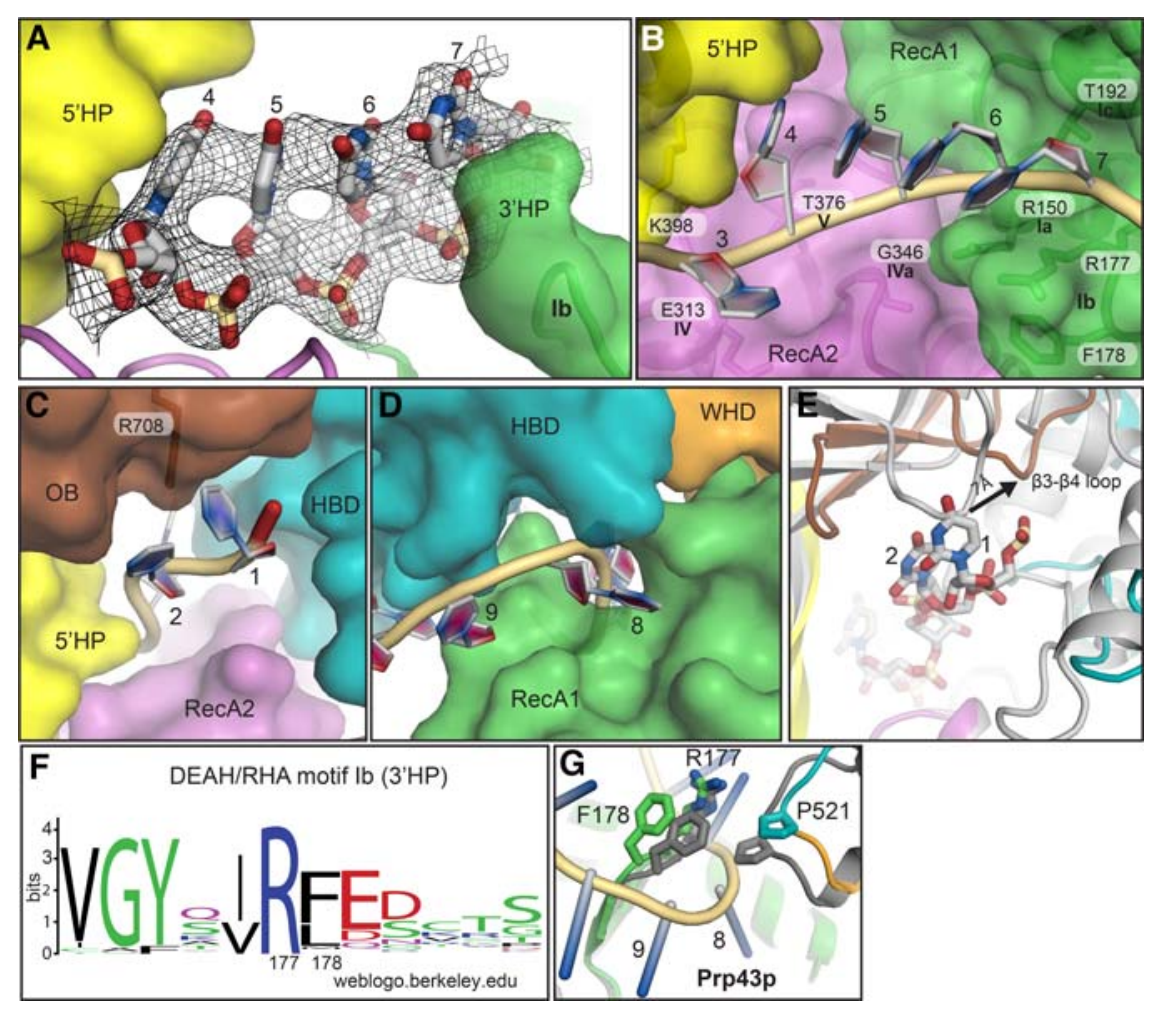

FIGURE 2. RNA binding by Prp43p involving motif $\mathrm{Ib}$. (A) A $2 \mathrm{mF}_{\mathrm{o}}-\mathrm{DF}_{\mathrm{c}}$ electron density omit map surrounding four stacked RNA bases is shown, averaged and contoured at $1.0 \sigma$. For clarity, only part of the RecA1 and RecA 2 domains are shown with surface representation of the $5^{\prime} \mathrm{HP}$ and motif Ib. $(B-D)$ Cartoon representation of RNA and surface representation of domains, demonstrating proximity of conserved motifs and bases, as indicated. $(B)$ Central four stacked bases. $(C)$ Entry channel. (D) Exit channel. (E) A comparison of Prp43p in the ADP-bound (PDB 3KX2) (gray) and the ADPNP-RNA-bound (colored) states, with the RecA2 domains superimposed to reveal movement of the OB fold required to accommodate RNA. $(F)$ The RNA-binding RF dipeptide at the tip of the $3^{\prime} \mathrm{HP}$, encompassing motif $\mathrm{Ib}$, is conserved. The sequence logo shows conservation within the $3^{\prime} \mathrm{HP}$ among human, Drosophila melanogaster, Arabidopsis thaliana, and yeast DEAH/RHA ATPases (see Materials and Methods for sequences). ( $G$ ) RNA binding is accommodated by opening of the RNA exit channel by separation of the $3^{\prime} \mathrm{HP}$ and a proline of the auxiliary domain. The closed RNA-free, ADP-bound structure is shown in gray; the open in RNA-ADPNP-bound structure is colored as in Figure 1.

In addition to the tilting of the auxiliary domains, in the RNA-ADPNP-Prp43p structure RecA2 rotates $15^{\circ}$ relative to RecA1 (Fig. 1D,E). This rotation moves motifs IV, IVa, and $\mathrm{V}$, all in RecA2, toward the RNA backbone (Fig. 3A); at the same time, the rotation moves conserved residues important for binding and hydrolysis of ATP in motif VI of RecA2 into close proximity of the ADPNP $\gamma$-phosphate (Fig. 3B and see below). This coordinated movement suggests a structural basis for how RNA binding stimulates the ATPase activity of Prp43p-by inducing a catalytically competent conformation of motif VI around the $\gamma$-phosphate.

Of the nine RNA nucleotides observed in complexes A and $\mathrm{B}$, the first three nucleotides at the $5^{\prime}$ end occupy the entryway to the RNA-binding channel (Fig. 2B,C), the next four nucleotides 4-7 stack and thread through the channel (Fig. $2 \mathrm{~A}, \mathrm{~B})$, and the final two nucleotides occupy the exitway (Fig. 2D). Whereas the backbone trace of the $5^{\prime}$ and $3^{\prime}$ tails in Prp43p deviates from MLE and NS3, the binding of four stacked nucleotides in the channel of Prp43p is the same as for the ATP-bound states of MLE and NS3 and consequently is a general feature (Gu and Rice 2010; Appleby et al. 2011; Prabu et al. 2015).

The $5^{\prime}$ end of the RNA binding pocket in the RNA-ADPNP-Prp43p structure, relative to the ADP-Prp43p structure (He et al. 2010), opens through movement of the $\beta 3-\beta 4$ loop of the OB-like fold by more than $7 \AA$ (Fig. 2E). In this open state, the $5^{\prime}$ end of the RNA is in close proximity to the OB-like fold and the HB domain. Supporting an interaction between the OB-like fold and RNA, mutations of R664, K704, and R708 of the $\mathrm{OB}$ fold decrease RNA stimulated ATPase activity (Walbott et al. 2010).

The central 4-nt RNA stack is held in place by RecA2, which is proximal to nucleotides 4 and 5, and by RecA1, which is proximal to nucleotides 6 and 7 (Fig. $2 \mathrm{~A}, \mathrm{~B})$. To investigate whether conserved features of RNA recognition by SF1 and SF2 ATPases were compatible with our low-resolution structure, where such interactions could not be identified unambiguously, we performed structural alignment of Prp43p bound to RNA with members of six SF2 ATPase families and three SF1 ATPase families bound to RNA. These alignments underscored the extraordinary conservation of nucleic acid binding mechanisms across SF1 and SF2 and supported similar binding by Prp43p (Supplemental Table S1, see Discussion). Specifically, the phosphate of nucleotide 4 is close to E313 of motif IV (Fig. 2B), consistent with an interaction between the phosphate and the amide of E313 conserved among both SF1 and SF2 members (Supplemental Table S1). This phosphate is also in proximity to $\mathrm{K} 398$ at the bottom of the $5^{\prime} \mathrm{HP}$ (Fig. 2B), a residue that is unique to and conserved as basic in the DEAH/RHA family (He et al. 2010), such as in MLE in which the side-chain of the equivalent R739 makes a hydrogen bond to a phosphate (Prabu et al. 2015). Consistent with a functionally relevant interaction between K398 and the RNA backbone, the mutation K398A confers a growth phenotype (Tanaka et al. 2007 and see below). The phosphate of nucleotide 5 is in close proximity to both the backbone amide of G346 in motif IVa (Fig. 2B), an interaction conserved across SF2 ATPases, and the nearly invariant side chain of T376 in motif V (Fairman-Williams et al. 2010), an interaction conserved in SF1 and SF2 ATPases (Supplemental Table S1). Consistent with a hydrogen bond between the side chain of T376 and 


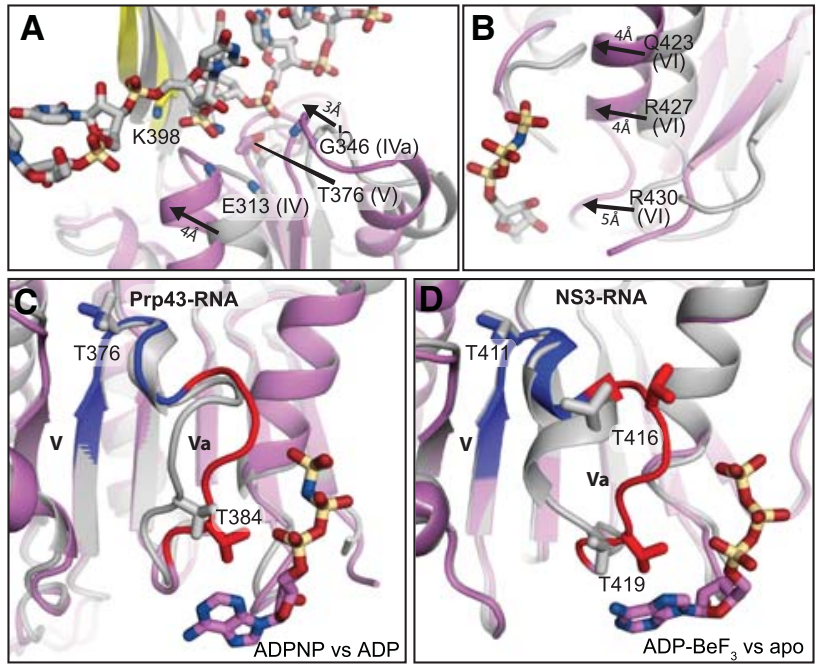

FIGURE 3. The rotation of RecA2 enables RNA and ADPNP binding, and alternative motif $\mathrm{Va}$ conformations implicate this element as an ATP sensor. $(A, B)$ The $9^{\circ}$ rotation of RecA2 enables binding of both RNA $(A)$ and ATP $(B)$, implicating a mechanism by which RNA binding stimulates ATPase activity. In panel $A$, the movement of motifs IV and IVa in the RNA- and ADPNP-bound structure, relative to the ADPbound structure (PDB 3KX2), is indicated by arrows. In panel $B$, the movement of motif VI in the RNA- and ADPNP-bound structure, relative to the ADP-bound structure, is indicated by arrows. In panels $A$ and $B$, the RecAl domain of Prp43p in the RNA-free, ADP-bound (gray) and the RNA- and ADPNP-bound (colored) states were superimposed. $(C, D)$ In Prp43, as in NS3, motif Va rearranges, and movement correlates with loss of the $\gamma$-phosphate. Panel $C$ compares the ADPNPand RNA-bound state versus ADP-bound state of Prp43p; panel $D$ compares the $\mathrm{ADP}-\mathrm{BeF}_{3}$ - and RNA-bound state versus the apo, RNA-bound state of NS3 (PDB 3O8R versus 3O8C). In each case, the RecA2 domain of the ATP-bound state (colored) was superimposed with the RecA2 domain of the contrasting states (gray). Blue highlights the static nature of motif $\mathrm{V}$ while red highlights the dynamic nature of motif $\mathrm{Va}$. The ATP analog is shown, colored by atom type. RNA is omitted for clarity.

RNA, the mutation T376V is lethal (Tanaka and Schwer 2006). As in other SF1 and SF2 ATPases, the phosphate of nucleotide 6 is in close proximity to the backbone of R150 of motif Ia, and the structure is consistent with an interaction between the phosphate of nucleotide 7 and the side chain of a strongly conserved threonine (T192) in motif Ic (Fairman-Williams et al. 2010).

The RNA stack is broken between bases 7 and 8 at the $3^{\prime}$ end near a second $\beta$-hairpin that we term the $3^{\prime} \mathrm{HP}$ (Figs. $1 B, C, 2 A)$. This hairpin is formed by residues $174-181$, which correspond to a motif $\mathrm{Ib}$ extension that is unique to and conserved within DEAH/RHA ATPases (Fig. 2F). The extension corresponds to an Arg-Phe dipeptide (R177-F178) located at the tip of the loop connecting the two strands (Figs. 1B, 2F). A conserved G173-Y174 dipeptide indicative of motif Ib (cf. Fig. 2F; Fairman-Williams et al. 2010) was previously suggested to parallel the conserved, RNA-binding GG dipeptide in motif Ib of DEAD-box ATPases (Sengoku et al. 2006), but the GY dipeptide in Prp43p is not structurally homologous to the DEAD-box GG motif and does not interact with RNA; in fact the distance between the $a$ carbon of G173 and the nearest
RNA is more than $13 \AA$. Instead, the DEAD-box GG motif is structurally analogous to the RF dipeptide (Supplemental Table S1). As with the $5^{\prime} \mathrm{HP}$, this $3^{\prime} \mathrm{HP}$ likely also serves as a bookend with R177 close enough to pack against the $3^{\prime}$ base of the RNA stack and with F178 in position to buttress R177 (Figs. 1B,C, 2A); we noted a similar arrangement of the equivalent RF dipeptide of motif Ib in MLE (Prabu et al. 2015).

\section{The $3^{\prime} \mathrm{HP}$ of Prp43p is required for ribosome biogenesis and spliceosome disassembly}

To determine the significance of the $3^{\prime} \mathrm{HP}$, we generated yeast strains with mutations at the tip of the $3^{\prime} \mathrm{HP}$. The mutant R177A exhibited a cold-sensitive (cs) phenotype, whereas the double-mutant R177A-F178A displayed a severe slow growth $(s l g)$ phenotype (Fig. 4A,B). The cs phenotype of $\mathrm{R} 177 \mathrm{~A}$ is consistent with a defect in unwinding, because a lower temperature is expected to stabilize the RNA or RNP target of Prp43p and thereby challenge a Prp43p mutant defective in destabilization. Across the RNA channel from R177 resides P521, just as P863 resides across the RNA channel from R470 of motif Ib in MLE (Prabu et al. 2015). This pair of residues may constrict the RNA channel, further promoting disruption of the RNA stack at the $3^{\prime}$ end on translocation (Fig. 2G). Indeed, the mutation P521A exacerbates the phenotype of the R177A mutation (Fig. 4C). To investigate whether the $3^{\prime} \mathrm{HP}$ and the $5^{\prime} \mathrm{HP}$ work in conjunction with each other, we generated a double mutant, R177A-K398A. Whereas the single mutations displayed cs (R177A) and slg (K398A) phenotypes (Tanaka et al. 2007), the double mutant R177A-K398A failed to grow, revealing a synthetic lethal relationship between the $3^{\prime} \mathrm{HP}$ and $5^{\prime} \mathrm{HP}$ mutations, suggesting these two elements do cooperate (Fig. 4D).

Because Prp43p promotes both ribosome biogenesis (Lebaron and Froment 2005; Combs et al. 2006; Leeds et al. 2006) and spliceosome disassembly (Arenas and Abelson 1997; Tanaka et al. 2007), we next tested whether the $3^{\prime} \mathrm{HP}$ was required for these functions. Specifically, we tested the cs mutant R177A after a 3-h shift to $16^{\circ} \mathrm{C}$ and found that, relative to wild type, (i) $35 \mathrm{~S}$ pre-rRNA increased and the $27 \mathrm{~S}$ and $20 \mathrm{~S}$ species, the products of $35 \mathrm{~S}$ processing, decreased concomitantly (Supplemental Fig. S2), and (ii) U3A lariat intron accumulated (Supplemental Fig. S2A), indicating a function for the $3^{\prime} \mathrm{HP}$ in ribosome biogenesis and spliceosome disassembly.

\section{The $3^{\prime} \mathrm{HP}$ of Prp43p is required for RNA unwinding}

To define the mechanistic role for the $3^{\prime} \mathrm{HP}$, we determined the impact of $3^{\prime} \mathrm{HP}$ mutations on the biochemical activities of $\operatorname{Prp} 43 \mathrm{p}$ in vitro. We first tested purified proteins (Supplemental Fig. S3A) in the presence of the G-patch cofactor Ntr1(1-120) (Tanaka et al. 2007) in an in vitro unwinding assay that utilized simple RNA/DNA duplexes with single-stranded RNA overhangs based on RNA designed 


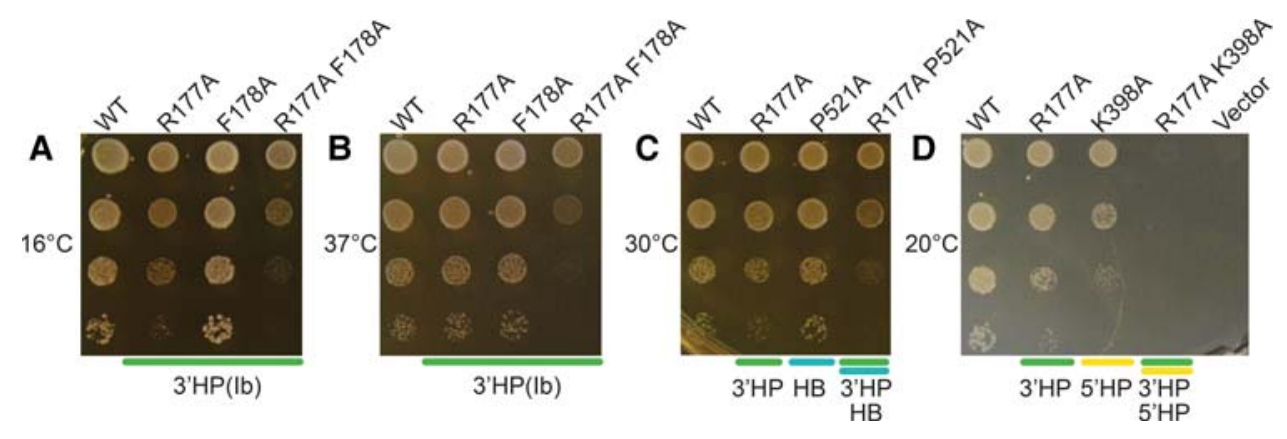

FIGURE 4. The RNA-interacting $3^{\prime} \mathrm{HP}$ of motif Ib is required for growth in the cold. $(A-D)$ A mutation of the RF dipeptide (R177A) at the tip of the $3^{\prime} \mathrm{HP}$ compromises growth at low temperature $(A$ versus $B)$ and synergizes with second site mutations in the dipeptide (F178A; $\left.B\right)$, in the nearby HB domain (P521A; C), and in the opposing, $5^{\prime} \mathrm{HP}$ bookend (K398A; D). Serial dilutions of yeast strains expressing Prp43p with the indicated mutations were tested for growth on solid rich medium (YPDA) $(A-C)$ or solid minimal medium containing 5-FOA $(D)$ and incubated at the indicated temperatures for $6 \mathrm{~d}(A), 1 \mathrm{~d}(B, C)$, or $3 \mathrm{~d}(D)$ to monitor growth. The domains encompassing the mutations are indicated below and color-coded as in Figure 1.

and experimentally tested to be devoid of secondary structure (Nallagatla et al. 2007; see Materials and Methods). Whereas wild-type Prp43p unwound a 21-bp duplex with a 27-nt $3^{\prime}$ overhang in a time-, Ntr1-, and ATP-dependent manner (Fig. 5A, lanes 1-5, 17), both the single Prp43p-R177A mutant and the double Prp43p-R177A-F178A mutant proteins failed to unwind (Fig. 5A, lanes 6-10 and 11-15). To determine whether the mutated proteins were deficient for unwinding due to a defect in binding RNA, we tested the proteins for binding to the unwinding substrate by an electrophoretic mobility shift assay (EMSA). Both mutants bound the duplex to the same extent as wild-type (Fig. 5B), ruling out a defect in RNA binding. To determine whether the mutated proteins were deficient for unwinding due to a defect in ATPase activity, we assayed the proteins for RNA-stimulated ATPase activity by thin layer chromatography. In contrast to a control mutant E216A, which is mutated in motif II and hydrolyzes ATP 30-fold lower than wild type (Fig. 5C), Prp43pR177A and Prp43p-R177A-F178A hydrolyzed ATP only approximately twofold slower than wild type (Fig. 5C; Supplemental Fig. S3B). Because the previously described mutant Prp43p-T384V displays clear unwinding activity despite more than a $50 \%$ decrease in ATPase activity (Tanaka and Schwer 2006; Tanaka et al. 2007), the modestly reduced ATPase activities of the $3^{\prime} \mathrm{HP}$ mutants are not likely to underlie their absolute deficiency in unwinding. Note that whereas a mutant, ATPase-deficient DEAH/RHA helicase Dhr1 unwinds a duplex substrate in the presence of ATP and under single-turnover conditions (Sardana et al. 2015), the ATPase-deficient Prp43p-E216A mutant failed to unwind a duplex under comparable conditions (Supplemental Fig. S3C), but did cross-link to UTP similar to wild-type Prp43p (data not shown), indicating that the NTPase (Tanaka and Schwer 2006) activity of Prp43p is essential for unwinding. Together, these observations imply that motif Ib in Prp43p and likely other DEAH/RHA ATPases promotes unwinding by specifically enabling translocation, presumably through capping the $3^{\prime}$ end of the RNA stack (see Discussion).

\section{Prp43p display $3^{\prime}-5^{\prime}$ directionality}

In unwinding a duplex, DExH-box ATPases are proposed to translocate on ssRNA and then, when the ATPase encounters the duplex, pry off the second strand. A requirement for a $3^{\prime}$ versus $5^{\prime}$ ssRNA overhang, as strictly observed for most translocating SF1 and SF2 ATPases, implicates a specific directionality of translocation for an ATPase (Fairman-Williams et al. 2010). While Prp43p, as a member of the DExH SF2 families, has the hallmarks of a $3^{\prime}$ to $5^{\prime}$ directional ATPase, earlier studies have nevertheless provided evidence for Prp43p-mediated unwinding of duplexes with either $3^{\prime}$ or $5^{\prime}$ overhangs, in the presence or absence of Ntr1 (Tanaka and Schwer 2006; Tanaka et al. 2007; Lebaron et al. 2009). However, these assays utilized substrates with long single-stranded overhangs with the potential to form additional secondary structures complicating the interpretation of unwinding assays. We found that Prp43p, in the presence of Ntr1(1-120), unwinds duplexes with a $3^{\prime}$ unstructured overhang much more efficiently than those with a $5^{\prime}$ unstructured overhang. Specifically, with $5^{\prime}$ and $3^{\prime}$ overhang substrates having an identical 28 -mer duplex, Prp43p utilized a $3^{\prime}$ overhang exclusively (Fig. 5D). With substrates having a 16-mer duplex, Prp43p similarly showed strong specificity for the substrate with a $3^{\prime}$ overhang (Supplemental Fig. 3D, compare lanes 2-4 with lanes 1214); in stark contrast, the $5^{\prime}$ to $3^{\prime}$ helicase Upf1 (Fiorini et al. 2012) showed strong specificity for the substrate with a $5^{\prime}$ overhang (Supplemental Fig. 3D, compare lanes 6-8 with lanes 16-18). Thus, our data imply that Prp43p translocates specifically in the $3^{\prime}$ to $5^{\prime}$ direction, as shown for many other members of the DExH-box families (Shuman 1993).

\section{The mechanism of RNA-stimulated ATPase activity by Prp43p}

As with other SF1 and SF2 ATPases, RNA binding stimulates the ATPase activity of Prp43p (Fig. 5C; Tanaka and Schwer 2006). While conformational differences between the ADP- 

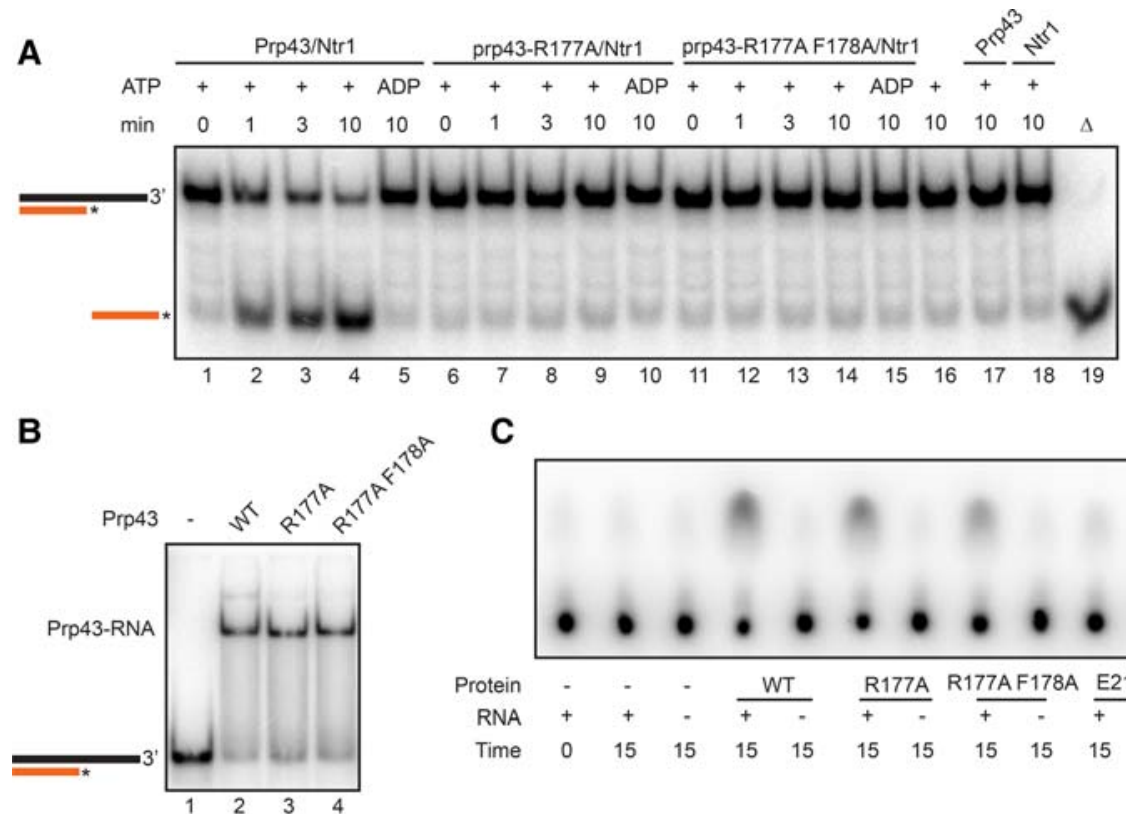

C
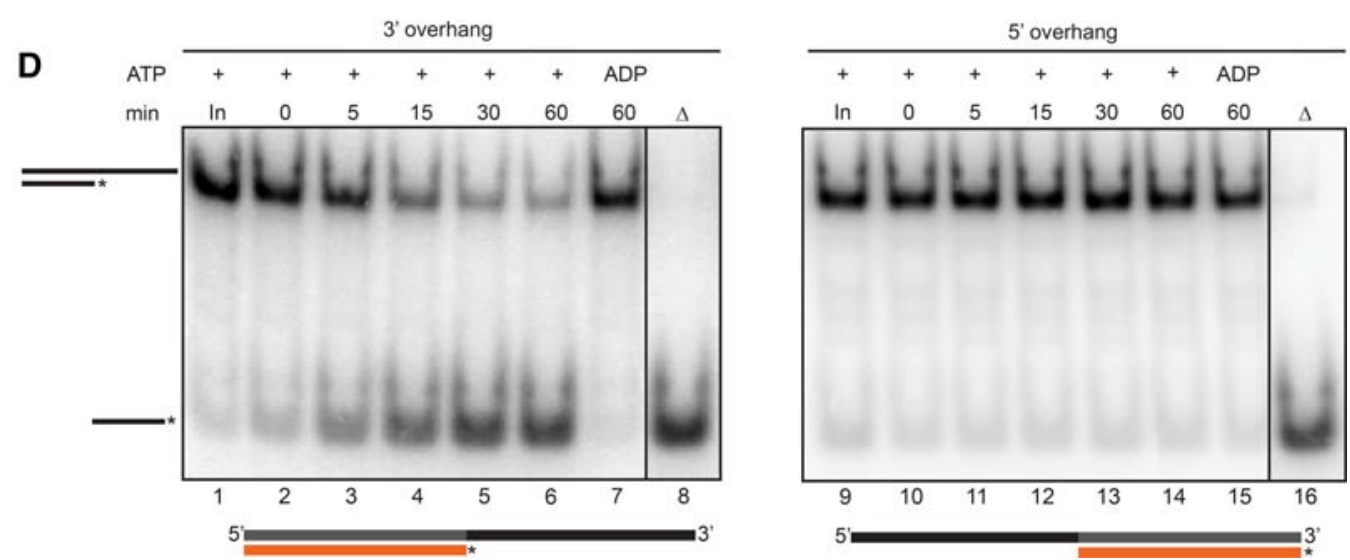

FIGURE 5. Motif Ib is not required for RNA binding or ATPase activity but is required for unwinding a $3^{\prime}$ overhang duplex. $(A)$ Mutations in the tip of the $3^{\prime} \mathrm{HP}$ encompassing motif Ib (R177A or R177A/F178A) compromise unwinding of a 21-bp RNA/DNA duplex having a 27-nt $3^{\prime}$ RNA overhang. (B) Mutations in motif Ib permit RNA binding. Binding of Prp43 to the RNA unwinding substrate used in panel $A$ was assayed by EMSA under conditions similar to the unwinding reactions but in the absence of ATP. The Prp43p-RNA complex is indicated. (C) Mutations in motif Ib permit ATPase activity. RNA-stimulated, Prp43-dependent ATPase activity was analyzed by TLC. The mutation E216A of motif II, the Walker B motif, was used as a negative control. $(D)$ Unwinding of either a $3^{\prime}$ or $5^{\prime}$ unstructured 32-nt RNA overhang substrate with an identical 28-mer duplex. Heat denaturation of the duplex $(\Delta)$ was used as a positive control for unwinding. A line separating lanes 7 and 8 or lanes 15 and 16 indicates that a single gel image was cut and arranged to juxtapose relevant lanes.

and ATP-RNA-bound structures of Prp43p and MLE, respectively, have been interpreted to be informative regarding the mechanisms of translocation (Prabu et al. 2015 and see Discussion), an analysis of such conformational rearrangements should help to explain how RNA binding can stimulate ATPase activity. Importantly, because we have solved the structure of Prp43p from the same organism bound to ADP or to ATP and RNA, we are able to make direct comparisons. The structure of Prp43p bound to ADPNP and RNA suggests that coupling of ATPase activity to RNA binding involves mainly conformational changes within the RecA2 domain. In the ADP-Prp43p structure, the conformation of the ATP binding motifs in RecAl are already positioned for hydrolysis and the spatial arrangement persists in the RNA-ADPNPPrp43p structure (and MLE [Prabu et al. 2015]). In the ADP-Prp43p structure (He et al. 2010; Walbott et al. 2010), the $\alpha$ and $\beta$ phosphates do not interact with RecA2 at all, but in the presence of RNA and ADPNP motif VI of RecA2 rotates into a position proximal to the $\beta$ and $\gamma$ phosphates (Fig. 3B, cf. Prabu et al. 2015) characteristic of all SF2 family helicases (Fairman-Williams et al. 2010). Further, the rotation moves Q423 of motif VI close to the $\gamma$-phosphate, a residue that is required for ATP hydrolysis in Prp43p (Martin et al. 2002). In summary, the structure implies that RNA binding induces a rotation required for the completion of the ATP binding pocket and catalytic core for hydrolysis. 


\section{Motif Va rearranges and is in a position to sense ATP hydrolysis and release}

Notably, while superimposition of the RecAl domain of the ADP-Prp43p structure (He et al. 2010; Walbott et al. 2010) and the RNA-ADPNP-Prp43p structure reveal no substantial rearrangements, superimposition of the RecA2 domains revealed that motif Va uniquely adopts different conformations, as validated by an omit map (Fig. 3C; Supplemental Fig. S1E). Strikingly, motif Va in NS3 also adopts different conformations depending on the nucleotide state (Fig. 3D; $\mathrm{Gu}$ and Rice 2010; Appleby et al. 2011). Further, we have found (analysis not shown) that, relative to the ADP-bound Prp43p structure, motif Va also adopts a unique conformation in the RNA- and ATP-bound conformation of MLE (Prabu et al. 2015) and the ATP-bound or RNA- and ATPbound conformations of Prp43p from C. thermophilum, as recently reported during the preparation of this manuscript (Tauchert et al. 2017).

In principle, the rearrangement of motif Va in Prp43p could reflect a sensitivity to the $\gamma$-phosphate of ADPNP, RNA, or both. However, the NS3 structures that show motif Va rearrangements are all bound to RNA (Fig. 3D) or DNA (Gu and Rice 2010) and differ only in their nucleotide-bound state, implying that the motif Va conformation in the Prp43p-ADPNP-RNA complex is due to the presence of $\gamma$ phosphate rather than RNA and that motif Va conformationally changes upon ATP hydrolysis. Indeed, presumably to effect translocation, in NS3 the conformation of motif Va adopted in response to ATP hydrolysis and release appears to stabilize an extended stack of five nucleotides by introducing an extra hydrogen bond to the central phosphate ( $\mathrm{Gu}$ and Rice 2010; Appleby et al. 2011).

Structural and mutagenic analysis of Prp43p, MLE, and NS3 suggest a mechanism by which conserved residues of motif Va sense release of the $\gamma$-phosphate and ADP. Motif Va harbors T384, an essential residue located in close proximity to the adenine ring and conserved in DEAH/RHA and NS3/NPH-II ATPases (Fairman-Williams et al. 2010). In both MLE and NS3 this threonine interacts with the adenine ring and forms a hydrogen bond to a conserved Arg within motif VI that interacts with the $\gamma$-phosphate $(\mathrm{Gu}$ and Rice 2010; Appleby et al. 2011; Prabu et al. 2015). Our Prp43p-ADPNP-RNA structure is consistent with Thr384 interacting similarly, and in support of the importance of such interactions for sensing ATP the mutations T384V and T384A are lethal in Prp43p (Tanaka and Schwer 2006).

Structural comparisons additionally suggest that motif $\mathrm{Va}$ dynamics may function to promote domain opening by destabilizing the closed, ATP-bound conformation. Specifically, with NS3, we found that superimposition of the RecA2 domain from the open, nucleotide-free state (Appleby et al. 2011) with the RecA2 domain of the ATP (ADP- $\left.\mathrm{BeF}_{3}\right)$ bound, closed state (Appleby et al. 2011), resulted in a steric clash between the nucleotide-free conformation of motif $\mathrm{Va}$ and motif Ia in RecA1 (Supplemental Fig. S4B). Similarly, with Prp43p, superimposition of the RecA2 domain from the ADP-state (He et al. 2010) with the RecA2 domain of the ATP- and RNA-bound, closed state also revealed a steric clash between the ADP conformation of motif $\mathrm{Va}$ and motif Ia in RecA1 (Supplemental Fig. S4A). A similar steric clash would likely manifest in closed, ATP-bound conformations of Hel308 and Mtr4, implying similar motif Va dynamics in these proteins (Supplemental Fig. S4C,D).

\section{DISCUSSION}

Among the SF2 families of nucleic acid-dependent ATPases (Ozgur et al. 2015), the unwinding mechanism of the DEAH/RHA family is the least well understood. In this work, we present the structure of the DEAH/RHA ATPase Prp43p in complex with ssRNA and the ATP analog ADPNP (Fig. 1). The structure reveals that conserved motifs in Prp43p are in close proximity to RNA in a manner analogous to RNA binding by other SF1 and SF2 RNA-dependent ATPases (Supplemental Table S1). Four central nucleotides are oriented into an RNA stack in which the $5^{\prime}$ end is bounded by an extended hairpin (Fig. 2), as observed in viral helicases (Jankowsky 2011), and the $3^{\prime}$ end is bounded by a DEAH/RHA specific variation of motif Ib, which manifests as an elongated $3^{\prime} \mathrm{HP}$ (Figs. 1, 2). The $3^{\prime} \mathrm{HP}$ is required for robust yeast growth, splicing, and ribosome biogenesis (Fig. 4; Supplemental Fig. S2), and while the $3^{\prime} \mathrm{HP}$ does not contribute significantly to RNA binding or ATP hydrolysis, the motif is critical for RNA unwinding, which we observe occurs with a strict $3^{\prime}$ to $5^{\prime}$ polarity (Fig. 5; Supplemental Fig. S3). Lastly, a comparison of this structure with the structure of RNA-free, ADP-bound Prp43p (He et al. 2010; Walbott et al. 2010) suggests how RNA binding stimulates ATP hydrolysis, and further that ATP hydrolysis induces rearrangements of motif $\mathrm{Va}$, paralleling analogous rearrangements of this motif in NS3 that have been implicated in translocation, suggesting a general role across DExH families in promoting translocation (Figs. 3, 6; Supplemental Fig. S4).

\section{Evidence for a mechanism of translocation by DEAH/RHA ATPases that parallels viral helicases and involves motif $\mathrm{Va}$}

The DExH box ATPases are thought to unwind RNA fundamentally by translocating $3^{\prime}$ to $5^{\prime}$ along ssRNA (Singleton et al. 2007; Jankowsky 2011). Given that SF1 and SF2 ATPases generally toggle in an ATP-dependent manner between an opened and closed orientation of the RecA domains, demonstrated directly for the DExH-box ATPase NS3 (Gu and Rice 2010; Appleby et al. 2011), the DExH box ATPases are thought to translocate by a reaction involving two overall steps in which the RecA domains toggle (Singleton et al. 2007; Jankowsky 2011), and in a coupled manner each alternates between a static, RNA-bound state and a dynamic state 
A
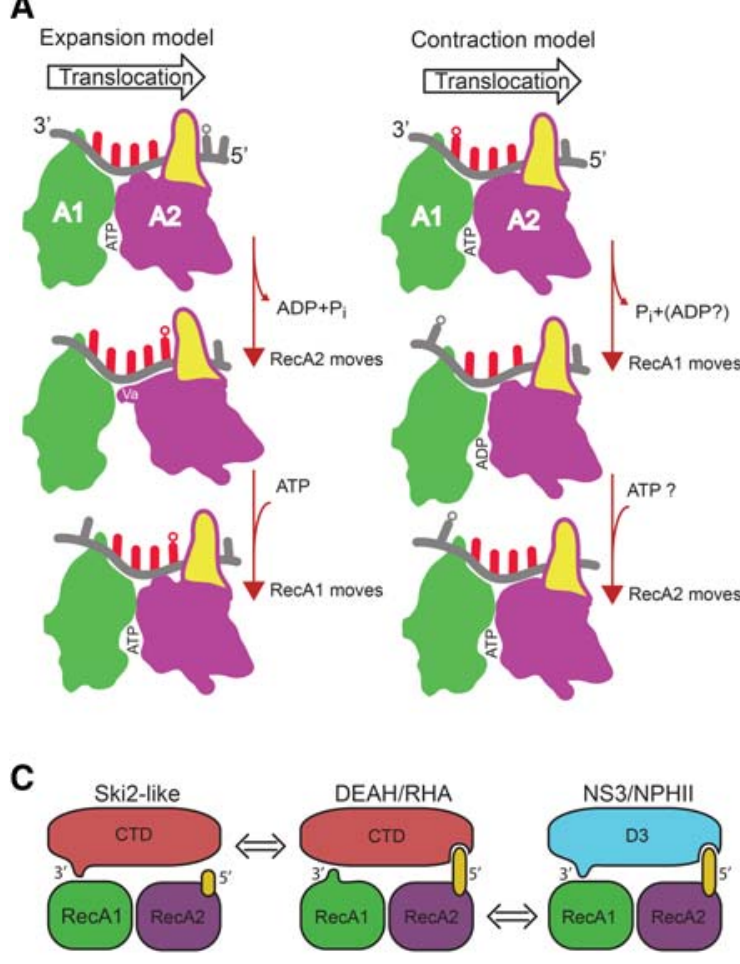

B

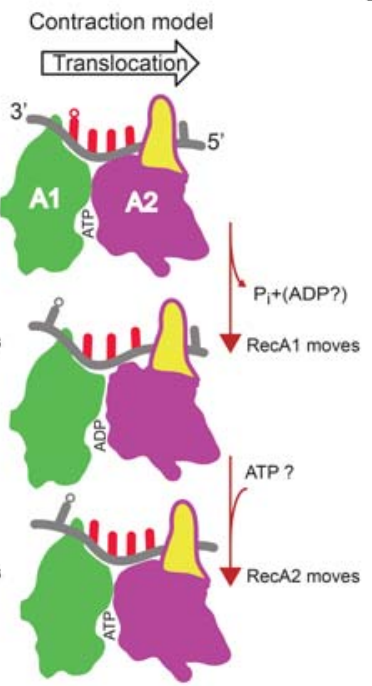

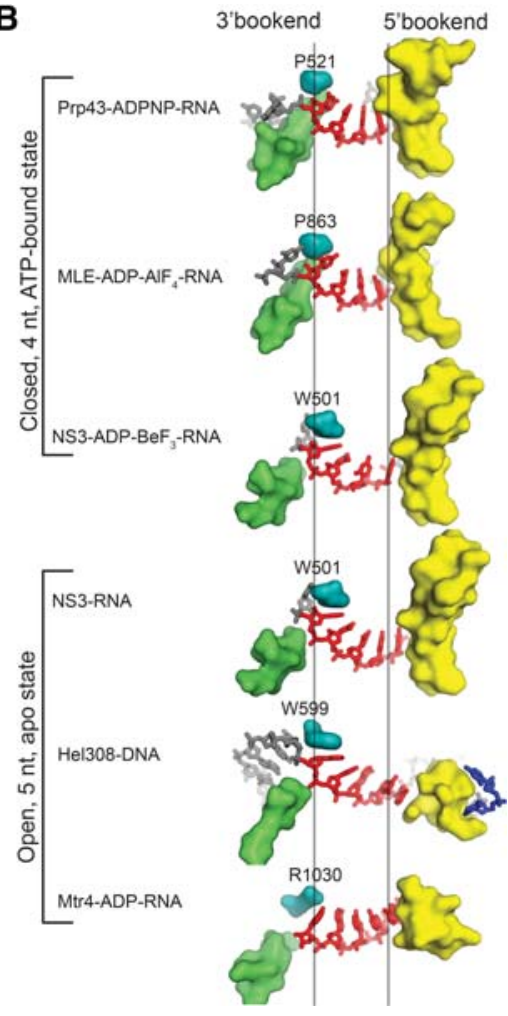

FIGURE 6. A translocation model for DEAH/RHA ATPases. (A) Two alternative translocation models, differing in the coupling of the ATPase cycle to RecA domain movement and in the number of stacked bases after Pi release. (B) All current structures of DExH box ATPases bound to RNAPrp43 (this work), MLE (PDB 5AOR), NS3 bound and not bound to nucleotide (PDB 3O8R and 3O8C), HEL308 (PDB 2P6R), and MTR4 (PDB 2XGJ)—show that closed, ATP-bound states bookend 4-nt RNA stacks (top), whereas open, apo states bookend 5-nt stacks (bottom). Stacked nucleotides are red; nonstacked residues are gray; blue indicates residues of a complementary strand that has been partially unwound in Hel308. Motif Ib is in green and corresponds to the $3^{\prime}$ bookend in Prp43 and MLE; the $3^{\prime}$ bookend in NS3, Hel308, and Mtr4, which derives from an auxiliary domain, is cyan, and the proline similarly positioned in Prp43 and MLE is also cyan; the $5^{\prime}$ bookends are yellow. $(C)$ Schematic representation of the chimeric structure of DEAH/RHA ATPases, which include elements structurally paralogous to NS3/NPHII or Ski2-like ATPases. The 3'- and 5' -bookends are represented as $3^{\prime}$ and $5^{\prime}$, respectively.

in which the corresponding RecA domain moves along RNA in the $5^{\prime}$ direction, much like an inchworm (Velankar et al. 1999). A key aim in determining the mechanism of unwinding and translocation is to define how movement of the two RecA domains along RNA couples to the cycle of ATP binding, hydrolysis, and release.

Previously, a comparison of the related DEAH/RHA ATPase MLE bound to RNA and an ATP transition state analog with Prp43p-ADP indicated movement of the RecA domains toward one another, in the ADP state (He et al. 2010; Walbott et al. 2010; Prabu et al. 2015). This movement suggested that ATP hydrolysis induces domain closure and that RecA2, through a "hook loop" in motif IVa, pulls the RNA toward RecAl (Prabu et al. 2015), resulting in movement of RecA1 in the $3^{\prime}$ to $5^{\prime}$ direction; such movement would likely lead to a stack of three bases (Fig. 6A, contraction model). At a later stage, RecA2 would in turn move in the $3^{\prime}$ to $5^{\prime}$ direction, regenerating the four base stack before another cycle of ATP binding, hydrolysis and release. In support of this model, an analogous but direct comparison of Prp43p in the ADPNP/RNA state versus the ADP state also shows that the RNA binding motif IVa in RecA2 moves closer to RecAl in the ADP bound state (Supplemental Fig. S5A). However, the Prp43p-ADP complex lacks RNA. To model how RNA might interact with Prp43p in the ADP conformation, we separately superimposed each RecA domain from the ADPNP/RNA structure along with the two bound nucleotides onto the corresponding RecA domains of the ADP structure (Supplemental Fig. S5B). The model demonstrates that the RecA domains in the ADP structure are not in an alignment that would allow binding to RNA through canonical interactions (Supplemental Table S1). Additionally, the RNA channel is occluded at the $3^{\prime}$ end of the Prp43p-ADP structure. Although Prp43p in the ADP state may bind RNA through noncanonical interactions, a simpler interpretation is that the ADP-bound crystal structure of Prp43p represents a state not compatible with RNA binding; note that translocation may still involve a conformation of Prp43p bound to both RNA and ADP but one that is different from the RNA free structure of Prp43p bound to ADP. Further arguing against the contraction model, a stack of three bases, implied by the ADP structure, has not been observed for any SF2 family 
member. Additionally, RNase protection assays of MLE indicate that the footprint of the ADP state is either similar to or larger than the footprint of the ATP state, as determined when bound by ADPNP or ADP-BeFx, respectively-not smaller as predicted by the model (Prabu et al. 2015).

An alternative translocation model is suggested by a comparison of Prp43p (and MLE) with members of the other DExH families, the Ski2-like and viral helicases (Fig. 6A, expansion model). Like Prp43p, in the nucleic acid- and ATPbound conformation, the viral helicase NS3 bookends a stack of four nucleotides (Fig. 6B). Further, in the nucleic acidbound but nucleotide-free conformation, NS3 (Gu and Rice 2010; Appleby et al. 2011), as well as the Ski2-like family members Hel308 (Büttner et al. 2007) and Mtr4 (Weir et al. 2010), bookend a 5-nt stack (Fig. 6B; Büttner et al. 2007; Gu and Rice 2010; Weir et al. 2010; Appleby et al. 2011), suggesting that ATP hydrolysis and release leads to a larger, not a smaller, separation of the RecA domains and a fundamental step size of one nucleotide as proposed for NS3 (Gu and Rice 2010; Appleby et al. 2011). The unique, nucleotide-dependent rearrangement of motif Va in Prp43p and NS3 further supports a parallel between the mechanisms of NS3 and Prp43p.

\section{A model for translocation, with a role for the DEAH/ RHA-specific $\mathbf{3}^{\prime} \mathbf{H P}$ of motif Ib}

In the expansion model for translocation (Fig. 6), the transitioning of Prp43p from binding a 4-nt RNA stack to a 5-nt stack requires that the $3^{\prime} \mathrm{HP}$ of RecAl remains fixed while the $5^{\prime} \mathrm{HP}$ of RecA 2 moves in the $5^{\prime}$ direction to capture another base; conversely, the subsequent transitioning of Prp43p from a 5-nt stack back to a 4-nt stack then requires that the $5^{\prime} \mathrm{HP}$ remain fixed while the $3^{\prime} \mathrm{HP}$ moves in the $5^{\prime}$ direction to exclude the $3^{\prime}$ base from the stack. This suggests that these hairpin bookends play a key role in translocation by defining the dynamic boundaries of the RNA stack. The $5^{\prime}$ bookend corresponds to an elongated $5^{\prime} \mathrm{HP}$ not only in Prp43p but more broadly in DEAH/RHA ATPases (Prabu et al. 2015) as well as viral ATPases ( $\mathrm{Gu}$ and Rice 2010; Appleby et al. 2011), and we note that the shorter $5^{\prime} \mathrm{HP}$ in Ski2-like ATPases similarly corresponds to a $5^{\prime}$ bookend (Weir et al. 2010) in addition to interacting directly with the unwinding end of a duplex substrate (Fig. 6B; Büttner et al. 2007). Within the $3^{\prime} \mathrm{HP}$, the best candidate for a $3^{\prime}$ bookend of Prp43p is Arg177 from RecA1, as in MLE (Prabu et al. 2015), whereas the $3^{\prime}$ bookends of the viral and the Ski2like ATPases (Kim et al. 1998; Büttner et al. 2007; Weir et al. 2010), arginine or tryptophan, derive from an auxiliary domain (Fig. 6B), which in the Ski2-like ATPases is part of the "ratchet helix." For example, in the Ski2-like ATPase Mtr4, R1030 within the ratchet helix is in a position to function as a 3 ' bookend (Weir et al. 2010); indeed, the mutant R1030A compromises unwinding (Taylor et al. 2014). Importantly, mutation of the $3^{\prime}$ bookends in Prp43p and NS3 (R177 and
W501, respectively) confers similar phenotypes; both mutations compromise unwinding but retain RNA binding and ATPase activity (Fig. 5A-C; Lin and Kim 1999; Preugschat et al. 2000), suggesting a common role for these bookends in translocation, such as in securing the $3^{\prime} \mathrm{HP}$ and RecAl on RNA as the two RecA domains open upon ATP hydrolysis and as RecA 2 moves in the $5^{\prime}$ direction.

Interestingly, the $3^{\prime} \mathrm{HP}$ of Prp43p and MLE encompasses motif Ib (Fig. 2F). In contrast to the RecA1 motifs Ia and Ic, which are largely conserved across SF2 families (Fairman-Williams et al. 2010), motif Ib varies considerably among SF2 ATPases and may thereby contribute to their distinct activities. In the DExH family, motif Ib folds as a $3^{\prime} \mathrm{HP}$ (Büttner et al. 2007; Gu and Rice 2010; He et al. 2010; Jackson et al. 2010; Walbott et al. 2010; Weir et al. 2010; Appleby et al. 2011; Halbach et al. 2012), which may correlate with binding to single stranded RNA/DNA (Supplemental Fig. S6A-G). In the RecG-like and RecQ-like (Singleton et al. 2001; Pike et al. 2009) families and the Rig-I and DEAD-box families (Mallam et al. 2012; Devarkar et al. 2016), motif Ib adopts an $\alpha$-helical structure; further, in the Swi/Snf family (e.g., Dürr et al. 2005), motif Ib adopts an extended loop conformation (Supplemental Fig. S6H,I). Except for RecQ, all of these ATPases interact with double stranded nucleic acid (Fairman-Williams et al. 2010), suggesting a function for these conformations in binding double stranded nucleic acid. In DEAH/RHA ATPases, as demonstrated for MLE and consistent with our structure of Prp43p, the $3^{\prime} \mathrm{HP}$, while preserving a main chain interaction with RNA (Supplemental Table S1), deviates from Ski2-like and NS3 ATPases in conserving long side chains at the tip of the $3^{\prime} \mathrm{HP}$ that are in a position to stack with RNA bases (Figs. 1B,C, 2F, 6B; Prabu et al. 2015). During submission of this manuscript, the structure of Prp43 from C. thermophilum was published bound to RNA and an ATP analog at $2.6 \AA$ resolution, and this structure along with functional studies similarly highlighted the 3'HP, termed the "hook turn," in bookending the RNA stack and promoting unwinding, although the correspondence with motif Ib was not recognized (Tauchert et al. 2017).

While the hook loop (motif IVa) in MLE was suggested to pull the RNA (Prabu et al. 2015), we suggest that motif IVa is important for displacing the incoming nucleotide into the RNA stack (Supplemental Fig. S7A-D), and in both MLE and NS3 (motif IVa is termed the Arg clamp in NS3), mutations of the corresponding amino acids compromise unwinding (Lam et al. 2003; Prabu et al. 2015).

A strict $3^{\prime}$ to $5^{\prime}$ directionality has implications for the target and mechanism of Prp43p/Ntr1 during the disassembly of the spliceosome. A recent study provided evidence that Prp43p targets the U2-branch site interaction for disruption (Fourmann et al. 2016). While the evidence implicated a model in which Prp43p engages the pre-mRNA upstream of the branch site and then translocates in a $5^{\prime}$ to $3^{\prime}$ direction, our data showing strict $3^{\prime}$ to $5^{\prime}$ directionality are inconsistent with such a model. 


\section{The ssRNA tunnel of Prp43p}

While we have found that the RecA2 domain including motif Va of DEAH/RHA ATPases shares similarity with the NS3/ $\mathrm{NPH}-\mathrm{II}$ family, the WH and HB domains of the auxiliary domains of DEAH/RHA ATPases share similarity with Ski2-like ATPases; as such the DEAH/RHA family functions as a chimera of viral and Ski2-like helicases (Fig. 6C). The structures of the DEAH/RHA ATPases Prp43p and MLE, as well as NS3/ NPH-II and Ski2-like ATPases (Büttner et al. 2007; Gu and Rice 2010; Weir et al. 2010; Appleby et al. 2011; Prabu et al. 2015), show that auxiliary domains together with the RecA domains enclose the RNA binding site and create a tunnel for ssRNA, suggesting a processive mechanism involving translocation; indeed NS3 has been demonstrated to function processively (Preugschat et al. 2000; Lam et al. 2003).

Despite the tunnel, the RNA is not topologically constrained, so tilting of the auxiliary domains beyond the $9^{\circ} \mathrm{ob}-$ served in the ADPNP/RNA state (Fig. 1D,E) could open the RNA tunnel and release ssRNA, thereby limiting processivity. Conversely, such opening would enable binding to internal RNA sites and thereby obviate the need to thread onto the $3^{\prime}$ end of RNA; in fact the structure of Prp43p-ADP- $\mathrm{BeF}_{3}$ from C. thermophilum displays such an open conformation (Tauchert et al. 2017). Testing models for translocation and processivity is an important goal for future studies of DEAH/RHA ATPases.

\section{MATERIALS AND METHODS}

\section{Protein purification}

See Supplemental Table S3 for list of plasmids used. Expression and initial purification of Prp43p from the $\mathrm{pET}-52 \mathrm{~b}$ plasmid in a BL21 (DE3) strain was performed as previously described (He et al. 2010), and then Prp43p was purified further on a 24-mL Superdex 200 size-exclusion column (GE Healthcare), equilibrated in buffer $\mathrm{E}(20 \mathrm{mM}$ Tris- $\mathrm{HCl}$ [pH 7.6], $200 \mathrm{mM} \mathrm{NaCl}, 0.5 \mathrm{mM}$ DTT, $10 \%$ glycerol). pET-52-Prp43p-R177A and pET-52Prp43p-R177A-F178A were generated using site-directed mutagenesis and used to express the corresponding mutated Prp43p proteins as described above (He et al. 2010). Wild-type Prp43p, Prp43pR177A, and Prp43p-R177A-F178A were also purified from E. coli upon expression from a pET15b plasmid, without proteolytic removal of the $\mathrm{HIS}_{6}$-tag from the purified protein. These proteins were purified as previously described (He et al. 2010), except that cells were lysed using a French press, and after imidazole elution from the $\mathrm{Ni}^{2+}$ chelating column the protein was dialyzed overnight against buffer A (20mM Tris- $\mathrm{HCl}$ [pH 7.5], $0.5 \mathrm{mM}$ EDTA, $0.5 \mathrm{mM}$ DTT, $10 \%$ glycerol) and loaded on a $1-\mathrm{mL}$ mono Q column (GE Healthcare). Peak fractions, eluted using a linear $50-500 \mathrm{mM}$ $\mathrm{NaCl}$ gradient in buffer A, were applied to a 24-mL Superdex 200 column equilibrated in buffer E. Upf1- $\Delta \mathrm{CH}$ was purified essentially as previously described (Fiorini et al. 2012), except using different lysis buffer $(20 \mathrm{mM}$ Tris- $\mathrm{HCl}[\mathrm{pH} 7.5], 200 \mathrm{mM} \mathrm{NaCl}, 0.1 \%$ NP40 [Sigma 74385], $20 \mathrm{mM}$ imidazole, 10\% glycerol, $100 \mu \mathrm{g} / \mathrm{mL}$ lysozyme, $1 \times$ protease inhibitor cocktail EDTA-Free [Roche]); calmodulin binding buffer (20 mM Tris- $\mathrm{HCl}$ [pH 7.5], $200 \mathrm{mM}$ $\mathrm{NaCl}, 0.1 \% \mathrm{NP} 40$ [Sigma 74385], $4 \mathrm{mM} \mathrm{CaCl}, 1 \mathrm{mM}$ DTT, $10 \%$ glycerol); and calmodulin elution buffer $(20 \mathrm{mM}$ Tris- $\mathrm{HCl}[\mathrm{pH}$ 7.5], $200 \mathrm{mM} \mathrm{NaCl}, 0.1 \%$ NP40 [Sigma 74385], 20 mM EGTA, 1 mM DTT, 10\% glycerol). His 10-Smt3-Ntr1(1-120) was purified essentially as previously described (Tanaka et al. 2007). Cells were lysed using a French press in buffer containing $50 \mathrm{mM}$ Tris-HCl (pH 7.5), $250 \mathrm{mM} \mathrm{NaCl}, 10 \%$ glycerol, $100 \mu \mathrm{g} / \mathrm{mL}$ lysozyme, and $1 \times$ protease inhibitor cocktail EDTA-Free (Roche). The protein was eluted with steps of 50,100, 200, and $400 \mathrm{mM}$ imidazole. Selected fractions were then applied to a $24 \mathrm{~mL}$ Superdex 75 column (GE Healthcare) equilibrated in buffer containing $50 \mathrm{mM}$ Tris- $\mathrm{HCl}$ (pH 7.5), $150 \mathrm{mM} \mathrm{NaCl}, 1 \mathrm{mM}$ EDTA, 2 mM DTT, 10\% glycerol. All proteins were stored at $-80^{\circ} \mathrm{C}$.

\section{Crystallization of the Prp43p-ADPNP- $U_{25}$ ternary complex}

To form the ternary complex, Prp43p was concentrated to $7 \mathrm{mg} / \mathrm{mL}$ $(\sim 80 \mu \mathrm{M})$ and incubated with $1 \mathrm{mM} \mathrm{MgCl}_{2}$ and $1 \mathrm{mM}$ TEAC purified ADPNP (Sigma), and a 1.8 molar excess of a 25 -mer, polyuridine RNA oligo (Dharmacon) for $1 \mathrm{~h}$ at $4^{\circ} \mathrm{C}$. To make the crystallization buffer, a solution containing $100 \mathrm{mM}$ MES-NaOH ( $\mathrm{pH}$ 6.0), $100 \mathrm{mM} \mathrm{NaOAc}, 9.5 \%$ PEG 10K, and an additive solution ( $20 \%$ acetonitrile, $5 \%$ isopropyl $\beta$-D-1-thiogalactopyranoside) were mixed in a 5:1 (v:v) ratio. Crystallization drops were formed by mixing $1.8 \mu \mathrm{L}$ of the crystallization buffer with $1.2 \mu \mathrm{L}$ of the ternary complex in 72-well Terasaki Microbatch plates (Molecular Dimensions). The plates were covered with paraffin oil and incubated at $19^{\circ} \mathrm{C}$. Thin plate-like crystals appeared overnight and reached their maximum dimensions of $\sim 150 \times 75 \times 5 \mu \mathrm{m}$ within $48 \mathrm{~h}$.

\section{Data collection and structure determination}

The crystals were transferred to a cryo-protection buffer containing 100 mM MES-NaOH (pH 6.0), 100 mM NaOAc, 10\% PEG 10K, $35 \%$ glycerol, harvested, and then flash frozen in liquid nitrogen. A $4.2 \AA$ data set was recorded at $100 \mathrm{~K}$ at beamline I911-3 at Max-lab (Lund, Sweden) and processed with XDS (Kabsch 2010). The Prp43p-ADP structure (3KX2) (He et al. 2010) was used as a search model for molecular replacement with Phaser (McCoy et al. 2007). Two copies of Prp43p were located in the asymmetric unit. $R_{\text {free }}$ was lowered to below $40 \%$ by refinement with phenix.refine (Afonine et al. 2012) using rigid body and translation-libration-screw (TLS) refinement with noncrystallographic symmetry (NCS) restraints between the two molecules. Subsequent rebuilding using COOT (Emsley et al. 2010) was performed in NCS-averaged $2 \mathrm{mF}_{\mathrm{o}}-\mathrm{DF}_{\mathrm{c}}$ maps for the polypeptide chains, and in nonaveraged $2 \mathrm{mF}_{\mathrm{o}}-\mathrm{DF}_{\mathrm{c}}$ maps for the RNA chains, facilitated by the RCrane (Keating and Pyle 2012) module. There is overall good density for all regions of the protein except for residues 52-55 and 363-364. During refinement with phenix.refine (Afonine et al. 2012), we applied model restraints derived from the Prp43p-ADP structure determined at $2.2 \AA$ resolution (PDB code $3 \mathrm{KX} 2$ ) (He et al. 2010), tight domain-wise NCS restraints, and secondary structure restraints. To avoid model bias, the $3^{\prime} \mathrm{HP}$ was not subject to such restraints. Individual sites, TLS, and group B factor parameters were refined. Prior to the final round of refinement, model geometry was optimized by real space refinement with imDFF (Croll and Andersen 
2016). Models were validated with MOLPROBITY (Chen et al. 2010).

\section{Unwinding}

In order to make unwinding data simple to interpret, a singlestranded RNA (ssRNA-76) (Nallagatla et al. 2007) designed and experimentally tested to be devoid of secondary structure was used as a model for the RNA part of the RNA/DNA hybrid duplex used as substrates in the unwinding assays. Prp43p and its cofactor Ntr1 (1-120) were preincubated on ice for $10 \mathrm{~min}$ before addition of substrate. Prp43p was preincubated with $2.5 \mathrm{nM}^{32} \mathrm{P}$-labeled duplex in $40 \mathrm{mM}$ Tris- $\mathrm{HCl}$ ( $\mathrm{pH} 7.0$ ), $0.5 \mathrm{mM} \mathrm{MgCl}_{2}$, and $2 \mathrm{mM}$ DTT on ice for $10 \mathrm{~min}$. Unwinding was initiated by addition of $\mathrm{ATP} / \mathrm{MgCl}_{2}$, or $\mathrm{ADP} / \mathrm{MgCl}_{2}$ as a control, to a final concentration of $1 \mathrm{mM}$, and assayed on ice (slower unwinding was observed at $30^{\circ} \mathrm{C}$ ). Unwinding with $\mathrm{Upf} 1 \Delta \mathrm{CH}$ was performed at $30^{\circ} \mathrm{C}$. Samples of $10 \mu \mathrm{L}$ were removed at various time points and quenched with $2 \mu \mathrm{L}$ of loading buffer (0.1 M Tris-HCl [pH 7.0]), 50\% glycerol, 20 mM EDTA, $0.5 \%$ SDS, and $0.1 \%$ NP40 (Sigma 74385) and analyzed on a native $6 \%$ or $8 \%$ polyacrylamide gel in $1 \times \mathrm{TBE}$ ( $89 \mathrm{mM}$ Tris-borate, $2 \mathrm{mM}$ EDTA). The gel was dried and exposed to a phosphor screen. Signal detection was done using a Storm PhosphorImager (Molecular Dynamics).

The RNA/DNA hybrid duplex substrates were prepared by annealing 25 pmol DNA oligo labeled with $\left[\gamma^{-}{ }^{32} \mathrm{P}\right]$ ATP using polynucleotide kinase and $20 \mathrm{pmol}$ cold RNA oligo in $100 \mu \mathrm{L}$ hybridization buffer (20 mM Hepes-KOH [pH 7.6], 0.5 M NaCl, 1 mM EDTA, and $0.1 \%$ SDS, Lee and Hurwitz 1992) by heating to $95^{\circ} \mathrm{C}$ for 5 min and then lowering the temperature $1 \%$ min to room temperature. To purify the annealed product, the duplex was separated from unbound oligo on a native $8 \%$ polyacrylamide gel in $1 \times$ TBE, $0.1 \%$ SDS, a gel slice containing the duplex was cut from the gel, and then the duplex was eluted from the gel slice in 0.4 $\mathrm{mL}$ of elution buffer (0.5 M ammonium acetate [pH 7.0], $0.1 \%$ SDS, 10 mM EDTA) (Lee and Hurwitz 1992) by incubation with rotation overnight at $4^{\circ} \mathrm{C}$. RNA and DNA oligos were purchased from IDT except for long RNA oligos that were generated by T7 RNA transcription (see below).

The long RNA-1 and RNA-2 oligos were prepared by T7 RNA transcription of a PCR product generated using either DNA-1 or DNA-2 as templates, a T7 promoter-rev oligo, and either DNA-1fwd or DNA-2-fwd oligos, respectively. RNA-1 annealed with DNA-UW1 generates a 16-bp duplex with a 44-nt, $3^{\prime}$ overhang substrate. RNA-2 annealed with DNA-UW2 generates a 16-bp duplex with a 44-nt, 5' overhang substrate. RNA-3 annealed with DNAUW3 generates a 21-bp duplex with a 27-nt, $3^{\prime}$ overhang substrate.

See Supplemental Table S2 for sequence of oligos used.

\section{ATPase activity}

ATPase reactions $(25 \mu \mathrm{L})$ contained $40 \mathrm{mM}$ Tris- $\mathrm{HCl}$ ( $\mathrm{pH} 7.0), 0.5$ $\mathrm{mM} \mathrm{MgCl}_{2}, 2 \mathrm{mM}$ DTT, $1 \mathrm{mM}$ premixed ATP/ $\mathrm{MgCl}_{2}$ "spiked" with $\left[\gamma-{ }^{32} \mathrm{P}\right]-\mathrm{ATP}$, and the indicated proteins and RNA [poly(A)]. Proteins in buffer E were added as one-tenth of the final volume to a final concentration of $25 \mathrm{nM}$ Prp43p and $50 \mathrm{nM}$ Ntr1 (1-120), resulting in a final $\mathrm{NaCl}$ concentration of $20 \mathrm{mM}$. In reactions containing both Prp43p and Ntr1 (1-120), the proteins were premixed 1:2 from stock solutions and incubated on ice for $10 \mathrm{~min}$ before dilution in buffer E. Reactions were incubated at $30^{\circ} \mathrm{C}$ for $10-60 \mathrm{~min}$ and stopped by adding EDTA to a final concentration of 0.1 M. Samples were assayed for ATPase activity by analyzing $1 \mu \mathrm{L}$ aliquots by polyethyleneimine-cellulose thin-layer chromatography with $0.15 \mathrm{M}$ formic acid, $0.15 \mathrm{M} \mathrm{LiCl}(\mathrm{pH} 3)$ as the liquid phase. The dried chromatographic plates were exposed to a phosphor screen and signal detection was done using a Storm PhosphorImager (Molecular Dynamics) to locate the positions of ATP and Pi.

\section{EMSA}

Reactions $(10 \mu \mathrm{L})$ contained $40 \mathrm{mM}$ Tris- $\mathrm{HCl}(\mathrm{pH}$ 7.0), $0.5 \mathrm{mM}$ $\mathrm{MgCl}_{2}, 2 \mathrm{mM}$ DTT, $2.5 \mathrm{nM}{ }^{32} \mathrm{P}$-labeled duplex, $25 \mathrm{nM}$ Prp43p, and $50 \mathrm{nM} \mathrm{Ntr1}(1-120)$ as indicated, and were incubated on ice for $10 \mathrm{~min}, 2.5 \mu \mathrm{L}$ loading buffer ( $50 \%$ glycerol, $0.2 \%$ Triton X$100)$ was added, and reactions were analyzed on a $6 \%-8 \%$ polyacrylamide gel in $0.25 \times$ TBE. The gel was dried and exposed to a phosphor screen. Signal was detected using a Storm PhosphorImager (Molecular Dynamics).

\section{Sequence logo around the RNA-binding RF dipeptide}

Multiple alignment of sequences from the following Swissprot entries were used: DHX8_HUMAN, DHX9_HUMAN, DHX15_ HUMAN, DHX16_HUMAN, DHX29_HUMAN, DHX30_HUMAN, DHX32_HUMAN, DHX33_HUMAN, DHX34_HUMAN, DHX35_ HUMAN, DHX36_HUMAN, DHX38_HUMAN, DHX40_HUMAN, DHX57_HUMAN, DQX1_HUMAN, YTDC2_HUMAN, A1Z9L3_ DROME, KZ_DROME, MLE_DROME, Q7K3M5_DROME, Q8SWT2_DROME, SPNE_DROME, Q9VIZ3_DROME, Q9VL25_ DROME, Q9VR29_DROME, Q9VWI5_DROME, Q9VX63_ DROME, Q9VY54_DROME, Q9VZ55_DROME, DHX15_ARATH, O23511_ARATH, Y4102_ARATH, Q0WVI8_ARATH, Q38800_ ARATH, DHX8_ARATH, Q8VY00_ARATH, Q93Y16_ARATH, Q9C6G0_ARATH, Q9C734_ARATH, Q9C873_ARATH, Q9C6F9_ ARATH, Q9FF84_ARATH, Q9FZC3_ARATH, Q9LXT8_ARATH, Q9LZQ9_ARATH, Q9SHK6_ARATH, Q9SJ58_ARATH, Q9SMG9_ ARATH, Q9ZU53_ARATH, DHR1_YEAST, DHR2_YEAST, PRP2_ YEAST, PRP16_YEAST, PRP22_YEAST, PRP43_YEAST, YL419_ YEAST. From the alignment, five amino acids prior and following the RNA-binding RF dipeptide for each of the above sequences were used as input to generate a sequence logo using WebLogo (http://weblogo.berkeley.edu/.)

\section{Northern blot}

Total RNA was extracted from $25-50 \mathrm{~mL}$ yeast cultures grown to an $\mathrm{OD}_{600} \sim 0.7$ using hot acidic phenol. Then, $10 \mu \mathrm{g}$ total RNA was either separated on a $1 \%$ agarose gel in $6 \%$ formaldehyde, $20 \mathrm{mM} 3-$ ( $N$-morpholino)propanesulfonic acid buffer and transferred by capillary action to HybondN (Amersham) to ultimately visualize prerRNA and mature rRNA, or separated on a denaturing $8 \%$ polyacrylamide gel in $1 \times \mathrm{TBE}$ and transferred semidry to HybondN to visualize pre-U3A and excised U3A intron. Membranes were probed with ${ }^{32}$ P-labeled oligos in Rapid-Hyb buffer (Amersham), and washed once with $5 \times$ SSC $(20 \times$ SSC is $3 \mathrm{M} \mathrm{NaCl}, 0.3 \mathrm{M}$ sodium citrate) and $0.1 \%$ SDS and once with $1 \times$ SSC and $0.1 \%$ SDS. Membranes were exposed to a phosphor screen and signal detection 
was done using a Storm PhosphorImager (Molecular Dynamics). See Supplemental Table 2 for sequence of oligos used.

\section{Yeast manipulations}

The parental S. cerevisiae strain yJPS549 was derived from BY4743 by replacing chromosomal PRP43 with KanMX4 after transformation with pJPS261 (pRS316-PRP43P-URA3) as described in Leeds et al. (2006). The pJPS298 plasmid that expresses wild-type PRP43 from pRS315, described in Leeds et al. (2006), was used as the parental plasmid for all site-directed mutagenesis to generate the described Prp43p mutations. The entire gene of PRP43 was sequenced to verify that only the expected mutations were present.

Yeast transformations were performed using the LiOAc method (Gietz and Schiestl 2007). After transformation, 5-fluoroorotic acid was used to counter-select against yeast that had not passively lost the PRP43P-URA3 plasmid (pJPS261). Yeast growth assays were performed by diluting yeast from overnight cultures grown in YPDA to an $\mathrm{OD}_{600}$ of $\sim 0.4$, then serial diluting in 10 -fold increments, and then spotting with a frogger on solid rich medium (YPDA; $1 \%$ yeast extract, $2 \%$ peptone, $2 \%$ glucose, $0.004 \%$ adenine sulfate, and $2 \%$ agar) or solid 5-FOA medium (5-FOA; $0.67 \%$ yeast nitrogen base, $0.2 \%$ drop-out mix-uracil, $2 \%$ glucose, $50 \mu \mathrm{g} / \mathrm{mL}$ uracil, $0.1 \%$ 5-FOA, and $2 \%$ agar) at the indicated temperatures.

\section{DATA DEPOSITION}

Coordinates and structure factors of the Prp43p-RNA-ADPNP structure have been deposited in the Protein Data Bank, with the entry code $5 \mathrm{I} 8 \mathrm{Q}$.

\section{SUPPLEMENTAL MATERIAL}

Supplemental material is available for this article.

\section{ACKNOWLEDGMENTS}

We thank Beate Schwer and Hervé Le Hir for plasmids. We thank the Staley laboratory for useful discussions and comments on this manuscript. This work was supported by grants from the National Institutes of Health (R01GM062264) to J.P.S. and from Danscatt, the Danish National Research Foundation, and a Hallas-Møller stipend from the Novo-Nordisk Foundation to G.R.A.

Received January 30, 2017; accepted April 10, 2017.

\section{REFERENCES}

Afonine PV, Grosse-Kunstleve RW, Echols N, Headd JJ, Moriarty NW, Mustyakimov M, Terwilliger TC, Urzhumtsev A, Zwart PH, Adams PD. 2012. Towards automated crystallographic structure refinement with phenix.refine. Acta Crystallogr Sect D Biol Crystallogr 68: 352-367.

Appleby TC, Anderson R, Fedorova O, Pyle AM, Wang R, Liu X, Brendza KM, Somoza JR. 2011. Visualizing ATP-dependent RNA translocation by the NS3 helicase from HCV. J Mol Biol 405: 1139-1153.
Arenas JE, Abelson JN. 1997. Prp43: an RNA helicase-like factor involved in spliceosome disassembly. Proc Natl Acad Sci 94: 11798-11802.

Büttner K, Nehring S, Hopfner KP. 2007. Structural basis for DNA duplex separation by a superfamily-2 helicase. Nat Struct Mol Biol 14: 647-652.

Chen VB, Arendall WB, Headd JJ, Keedy DA, Immormino RM, Kapral GJ, Murray LW, Richardson JS, Richardson DC. 2010. MolProbity: all-atom structure validation for macromolecular crystallography. Acta Crystallogr Sect D Biol Crystallogr 66: 12-21.

Chen YL, Capeyrou R, Humbert O, Mouffok S, Kadri YA, Lebaron S, Henras AK, Henry Y. 2014. The telomerase inhibitor Gnolp/ PINX1 activates the helicase Prp43p during ribosome biogenesis. Nucleic Acids Res 42: 7330-7345.

Christian H, Hofele RV, Urlaub H, Ficner R. 2013. Insights into the activation of the helicase Prp43 by biochemical studies and structural mass spectrometry. Nucleic Acids Res 42: 1162-1179.

Combs D, Nagel R, Ares M, Stevens SW. 2006. Prp43p is a DEAH-box spliceosome disassembly factor essential for ribosome biogenesis. Mol Cell Biol 26: 523-534.

Croll TI, Andersen GR. 2016. Re-evaluation of low-resolution crystal structures via interactive molecular-dynamics flexible fitting (iMDFF): a case study in complement C4. Acta Crystallogr Sect D Struct Biol 72: 1006-1016.

Devarkar SC, Wang C, Miller MT, Ramanathan A, Jiang F, Khan AG, Patel SS, Marcotrigiano J. 2016. Structural basis for $\mathrm{m} 7 \mathrm{G}$ recognition and 2'-O-methyl discrimination in capped RNAs by the innate immune receptor RIG-I. Proc Natl Acad Sci 113: 596-601.

Dürr H, Körner C, Müller M, Hickmann V, Hopfner KP. 2005. X-ray structures of the Sulfolobus solfataricus SWI2/SNF2 ATPase core and its complex with DNA. Cell 121: 363-373.

Emsley P, Lohkamp B, Scott WG, Cowtan K. 2010. Features and development of Coot. Acta Crystallogr D Biol Crystallogr 66: 486-501.

Fairman-Williams ME, Guenther UP, Jankowsky E. 2010. SF1 and SF2 helicases: family matters. Curr Opin Struct Biol 20: 313-324.

Fiorini F, Bonneau F, Le Hir H. 2012. Biochemical characterization of the RNA helicase UPF1 involved in nonsense-mediated mRNA decay. Methods Enzymol 511: 255-274.

Fourmann J, Dybkov O, Agafonov DE, Marcel J. 2016. The target of the DEAH-box NTPase Prp43 in S. cerevisiae spliceosomes is the U2 snRNP-intron interaction. Elife 5: e15564.

Frick DN. 2007. The hepatitis C virus NS3 protein: a model RNA helicase and potential drug target. Curr Issues Mol Biol 9: 1-20.

Gietz RD, Schiestl RH. 2007. High-efficiency yeast transformation using the LiAc/SS carrier DNA/PEG method. Nat Protoc 2: 31-34.

Gu M, Rice CM. 2010. Three conformational snapshots of the hepatitis $\mathrm{C}$ virus NS3 helicase reveal a ratchet translocation mechanism. Proc Natl Acad Sci 107: 521-528.

Halbach F, Rode M, Conti E. 2012. The crystal structure of S. cerevisiae Ski2, a DExH helicase associated with the cytoplasmic functions of the exosome. RNA 18: 124-134.

He Y, Andersen GR, Nielsen KH. 2010. Structural basis for the function of DEAH helicases. EMBO Rep 11: 180-186.

Heininger AU, Hackert P, Andreou AZ, Boon K, Memet I, Prior M, Clancy A, Schmidt B, Urlaub H, Schleiff E, et al. 2016. Protein cofactor competition regulates the action of a multifunctional RNA helicase in different pathways. RNA Biol 13: 320-330.

Jackson RN, Klauer AA, Hintze BJ, Robinson H, van Hoof A, Johnson SJ. 2010. The crystal structure of Mtr4 reveals a novel arch domain required for rRNA processing. EMBO J 29: 2205-2216.

Jankowsky E. 2011. RNA helicases at work: binding and rearranging. Trends Biochem Sci 36: 19-29.

Kabsch W. 2010. XDS. Acta Crystallogr Sect D Biol Crystallogr 66: 125-132.

Keating KS, Pyle AM. 2012. RCrane: semi-automated RNA model building. Acta Crystallogr Sect D Biol Crystallogr 68: 985-995.

Kim JL, Morgenstern KA, Griffith JP, Dwyer MD, Thomson JA, Murcko MA, Lin C, Caron PR. 1998. Hepatitis C virus NS3 RNA 
helicase domain with a bound oligonucleotide: the crystal structure provides insights into the mode of unwinding. Structure 6: 89-100.

Kudlinzki D, Schmitt A, Christian H, Ficner R. 2012. Structural analysis of the C-terminal domain of the spliceosomal helicase Prp22. Biol Chem 393: 1131-1140.

Lam AMI, Keeney D, Frick DN. 2003. Two novel conserved motifs in the hepatitis C virus NS3 protein critical for helicase action. J Biol Chem 278: 44514-44524.

Lebaron S, Froment C. 2005. The splicing ATPase prp43p is a component of multiple preribosomal particles. Mol Cell Biol 25: 9269-9282.

Lebaron S, Papin C, Capeyrou R, Chen YL, Froment C, Monsarrat B, Caizergues-Ferrer M, Grigoriev M, Henry Y. 2009. The ATPase and helicase activities of Prp43p are stimulated by the G-patch protein Pfalp during yeast ribosome biogenesis. EMBO $J$ 28: 3808-3819.

Lee C, Hurwitz J. 1992. A new RNA helicase isolated from HeLa cells that catalytically translocates in the $3^{\prime}$ to $5^{\prime}$ direction. J Biol Chem 267: 4398-4407.

Leeds N, Small E, Hiley SL, Hughes TR, Staley JP. 2006. The splicing factor Prp43p, a DEAH box ATPase, functions in ribosome biogenesis. Mol Cell Biol 26: 513-522.

Lin C, Kim JL. 1999. Structure-based mutagenesis study of hepatitis C virus NS3 helicase. J Virol 73: 8798-8807.

Mallam AL, Del Campo M, Gilman B, Sidote DJ, Lambowitz AM. 2012. Structural basis for RNA-duplex recognition and unwinding by the DEAD-box helicase Mss116p. Nature 490: 121-125.

Martin A, Schneider S, Schwer B. 2002. Prp43 is an essential RNA-dependent ATPase required for release of lariat-intron from the spliceosome. J Biol Chem 277: 17743-17750.

Mayas RM, Maita H, Semlow DR, Staley JP. 2010. Spliceosome discards intermediates via the DEAH box ATPase Prp43p. Proc Natl Acad Sci 107: 10020-10025.

McCoy AJ, Grosse-Kunstleve RW, Adams PD, Winn MD, Storoni LC, Read RJ. 2007. Phaser crystallographic software. J Appl Crystallogr 40: 658-674.

Nallagatla SR, Hwang J, Toroney R, Zheng X, Cameron CE, Bevilacqua PC. 2007. 5'-triphosphate-dependent activation of PKR by RNAs with short stem-loops. Science 318: 1455-1458.

Nguyen THD, Li J, Galej WP, Oshikane H, Newman AJ, Nagai K. 2013. Structural basis of Brr2-Prp8 interactions and implications for U5 snRNP biogenesis and the spliceosome active site. Structure 21: 910-919.

Ozgur S, Buchwald G, Falk S, Chakrabarti S, Prabu JR, Conti E. 2015. The conformational plasticity of eukaryotic RNA-dependent ATPases. FEBS J 282: 850-863.

Pena V, Jovin SM, Fabrizio P, Orlowski J, Bujnicki JM, Lührmann R, Wahl MC. 2009. Common design principles in the spliceosomal RNA helicase Brr2 and in the Hel308 DNA helicase. Mol Cell 35: 454-466.

Pike ACW, Shrestha B, Popuri V, Burgess-Brown N, Muzzolini L, Costantini S, Vindigni A, Gileadi O. 2009. Structure of the human RECQ1 helicase reveals a putative strand-separation pin. Proc Natl Acad Sci 106: 1039-1044.

Prabu JR, Müller M, Thomae AW, Schüssler S, Bonneau F, Becker PB, Conti E. 2015. Structure of the RNA helicase MLE reveals the molec- ular mechanisms for uridine specificity and RNA-ATP coupling. Mol Cell 60: 487-499.

Preugschat F, Danger DP, Carter LH, Davis RG, Porter DJT. 2000. Kinetic analysis of the effects of mutagenesis of W501 and V432 of the hepatitis C virus NS3 helicase domain on ATPase and strandseparating activity. Biochemistry 39: 5174-5183.

Pyle AM. 2008. Translocation and unwinding mechanisms of RNA and DNA helicases. Annu Rev Biophys 37: 317-336.

Robert-Paganin J, Réty S, Leulliot N. 2015. Regulation of DEAH/RHA helicases by G-patch proteins. Biomed Res Int 2015: 931857.

Sardana R, Liu X, Granneman S, Zhu J, Gill M, Papoulas O, Marcotte EM, Tollervey D, Correll CC, Johnson AW. 2015. The DEAH-box helicase Dhr1 dissociates U3 from the pre-rRNA to promote formation of the central pseudoknot. PLoS Biol 13: e1002083.

Sengoku T, Nureki O, Nakamura A, Kobayashi S, Yokoyama S. 2006. Structural basis for RNA unwinding by the DEAD-box protein Drosophila Vasa. Cell 125: 287-300.

Shuman S. 1993. Vaccinia virus RNA helicase. Directionality and substrate specificity. J Biol Chem 268: 11798-11802.

Singleton MR, Scaife S, Wigley DB. 2001. Structural analysis of DNA replication fork reversal by RecG. Cell 107: 79-89.

Singleton MR, Dillingham MS, Wigley DB. 2007. Structure and mechanism of helicases and nucleic acid translocases. Annu Rev Biochem 76: $23-50$.

Tanaka N, Schwer B. 2006. Mutations in PRP43 that uncouple RNA-dependent NTPase activity and pre-mRNA splicing function. Biochemistry 45: 6510-6521.

Tanaka N, Aronova A, Schwer B. 2007. Ntr1 activates the Prp43 helicase to trigger release of lariat-intron from the spliceosome. Genes Dev 21: 2312-2325.

Tanner NK, Linder P. 2001. DExD/H box RNA helicases: from generic motors to specific dissociation functions. Mol Cell 8: 251-262.

Tauchert MJ, Fourmann J-B, Christian H, Lührmann R, Ficner R. 2016. Structural and functional analysis of the RNA helicase Prp43 from the thermophilic eukaryote Chaetomium thermophilum. Acta Crystallogr Sect F Struct Biol Commun 72: 112-120.

Tauchert MJ, Fourmann J-B, Lührmann R, Ficner R. 2017. Structural insights into the mechanism of the DEAH-box RNA helicase Prp43. Elife 6: e21510.

Taylor LL, Jackson RN, Rexhepaj M, King AK, Lott LK, van Hoof A, Johnson SJ. 2014. The Mtr4 ratchet helix and arch domain both function to promote RNA unwinding. Nucleic Acids Res 42: 13861-13872.

Velankar SS, Soultanas P, Dillingham MS, Subramanya HS, Wigley DB. 1999. Crystal structures of complexes of PcrA DNA helicase with a DNA substrate indicate an inchworm mechanism. Cell 97: 75-84.

Walbott H, Mouffok S, Capeyrou R, Lebaron S, Humbert O, van Tilbeurgh H, Henry Y, Leulliot N. 2010. Prp43p contains a processive helicase structural architecture with a specific regulatory domain. EMBO J 29: 2194-2204.

Weir JR, Bonneau F, Hentschel J, Conti E. 2010. Structural analysis reveals the characteristic features of Mtr4, a DExH helicase involved in nuclear RNA processing and surveillance. Proc Natl Acad Sci 107: 12139-12144. 

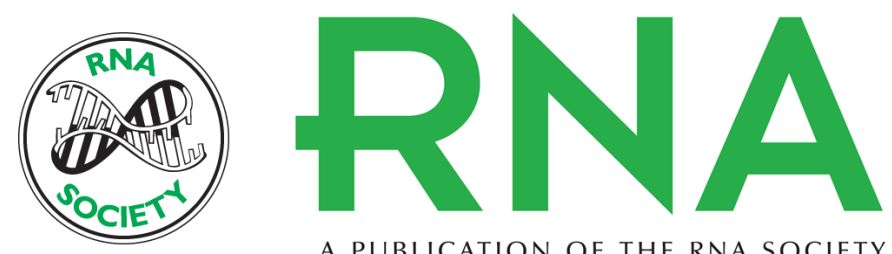

A PUBLICATION OF THE RNA SOCIETY

\section{Structure of the DEAH/RHA ATPase Prp43p bound to RNA implicates a pair of hairpins and motif $\mathrm{Va}$ in translocation along RNA}

Yangzi He, Jonathan P. Staley, Gregers Rom Andersen, et al.

RNA 2017 23: 1110-1124 originally published online April 17, 2017

Access the most recent version at doi:10.1261/rna.060954.117

\section{Supplemental http://rnajournal.cshlp.org/content/suppl/2017/04/17/rna.060954.117.DC1 Material}

References This article cites 60 articles, 21 of which can be accessed free at: http://rnajournal.cshlp.org/content/23/7/1110.full.html\#ref-list-1

Creative This article is distributed exclusively by the RNA Society for the first 12 months after the Commons License full-issue publication date (see http://rnajournal.cshlp.org/site/misc/terms.xhtml). After 12 months, it is available under a Creative Commons License (Attribution-NonCommercial 4.0 International), as described at http://creativecommons.org/licenses/by-nc/4.0/.

Email Alerting Receive free email alerts when new articles cite this article - sign up in the box at the Service top right corner of the article or click here. 